\title{
MULHERES CIENTISTAS NA QUÍMICA BRASILEIRA
}

\author{
Naiane Naidek ${ }^{\mathrm{a}}$, Yane H. Santos ${ }^{\mathrm{a}}$, Patricia Soares ${ }^{\mathrm{a}}$, Renata Hellinger ${ }^{\mathrm{a}}$, Thayna Hack ${ }^{\mathrm{a}}$ e Elisa S. Orth ${ }^{\mathrm{a}, *,(1)}$ \\ aDepartamento de Química, Universidade Federal do Paraná, 81531-990 Curitiba - PR, Brasil
}

Recebido em 20/12/2019; aceito em 15/04/2020; publicado na web em 29/05/2020

\begin{abstract}
WOMEN SCIENTISTS IN THE BRAZILIAN CHEMISTRY. Brazil's gender gaps numbers are scarce in the field of chemistry. Thus, the motivation of this work is to perform a data survey considering all levels of the academic career and per Brazilian region. The data collected shows a general trend observed in all scenarios, whereas the higher the career level the lower the number of women inserted. Women dominate in the early stages of the scientific careers, such as postgraduate programs (52\%) but become minority (42\%) when they get positions as university professors. The disparity is higher at positions of great recognition, e.g., member of the Brazilian Academy of Science (18\%) or the highest level of CNPQ research productivity fellowship "1A" (12\%). Other career indicators such as research grants approval, authorship in recognized international journals and in highly cited articles authored by Brazilian scientists, show low female representativity. Leadership positions in scientific societies and funding agencies are alarming (6\%), where many organizations never had a woman president. The world needs more female references in science and surely Brazil has many great women in the field of chemistry that deserve recognition. The present study sheds light to the awareness of the Brazilian scenario.
\end{abstract}

Keywords: gender parity, feminine representation, woman in science.

\section{MULHERES CIENTISTAS NO BRASIL: UMA VISÃO GERAL}

A paridade de gênero é uma temática mundial de crescente interesse, principalmente porque diversos dados apontam que uma maior representação feminina nas diversas esferas impulsiona o crescimento e desenvolvimento dos países. ${ }^{1}$ Além disso, a presença feminina no mercado de trabalho tem um impacto econômico significativo. Segundo a Organização Internacional do Trabalho (OIT), a redução de $25 \%$ da desigualdade de gênero no mercado de trabalho até 2025 poderá gerar um aumento no PIB de $4 \%$ nos países da América Latina. ${ }^{2}$

O relatório "The Global Gender Gap Report” do World Economic Forum mostra a situação de diversos países com relação a disparidade de gênero. O índice é obtido através de uma metodologia complexa em que avalia quatro áreas principais: saúde e sobrevivência, empoderamento político, nível educacional e participação econômica/oportunidade, sendo analisadas 14 variáveis, retiradas de dados publicados em organizações internacionais, como a Organização Internacional do Trabalho, o Programa das Nações Unidas para o Desenvolvimento e a Organização Mundial da Saúde. Esses parâmetros são avaliados com uma pontuação entre 0 e 1 , em que 0 significa imparidade e 1 paridade de gênero. Segundo o relatório publicado em 2018, em que foram avaliados 149 países, o Brasil está no $95^{\circ}$ lugar no ranking dos países, obtendo uma média de 0,681. Porém, o Brasil alcançou o primeiro lugar nos índices de Saúde e Sobrevivência e Nível educacional, em que apresentou uma pontuação bem elevada de 0,980 e 1,000 respectivamente. Em contrapartida, no quesito empoderamento político, o Brasil apresentou uma das menores pontuações do mundo $\left(112^{\circ}\right.$ colocado) sendo de apenas 0,101 .

No Brasil, a participação das mulheres vem crescendo no mercado de trabalho, sendo que, segundo o Ministério do Trabalho, a representação feminina aumentou de 40,8\% em 2007 para 44\% em 2016. Contudo, apesar de positivo o crescimento, esse número está abaixo do ideal, uma vez que o Instituto Brasileiro de Geografia e Estatística (IBGE) informa que as mulheres são a maioria na nossa

*e-mail: elisaorth@ufpr.br sociedade (51\%). Além disso, segundo o IBGE (2018), as mulheres possuem maior nível de instrução, tanto em nível de Ensino Médio quanto para Ensino Superior, ou seja, o engajamento de mulheres nestes níveis educacionais (seja por frequência ou continuidade) é maior que a dos homens. ${ }^{3}$

Ao longo dos anos, a inclusão das mulheres nas universidades (educação terciária) e como cientistas foi ocorrendo gradativamente, sendo mais evidente no último século. No panorama nacional (considerando todas as áreas, no ano de 2017), se analisarmos a população brasileira entre $24-35$ anos apenas $34 \%$ desses jovens possuem educação terciária, e nesse cenário a representação feminina é de $20 \%$, sendo $14 \%$ apenas de homens. Além disso, no Brasil é verificada uma inequidade regional da população com educação terciária. Enquanto $33 \%$ dos jovens adultos possuem educação terciária no Distrito Federal (capital brasileira e estado com o maior PIB per capita), apenas $8 \%$ dos adultos possuem educação terciária no estado do Maranhão (estado com o menor PIB per capita). ${ }^{4}$

Entretanto, apesar da representatividade das mulheres com formação universitária ser superior à dos homens, quando verificamos a ascensão ao longo da carreira profissional científica, citações e Prêmio Nobel, os homens ainda se destacam. Um estudo da Elsevier (Gender in the Global Research Landscape) mostrou que no Brasil, no período de 2011-2015 e considerando todas as áreas de pesquisa, as mulheres constituíam $49 \%$ da população de pesquisadores. ${ }^{3}$ Entretanto, quando analisado o número de pesquisadores registrados no Conselho Nacional de Desenvolvimento Científico e Tecnológico (CNPq) em 2018, nas áreas de química, física e matemática existe uma disparidade de gênero, em que $68 \%$ é composto por homens e $32 \%$ por mulheres..$^{5}$ Ao analisar as principais áreas da química: físico-química, orgânica, analítica e inorgânica, observa-se um valor crescente de representatividade feminina como pesquisadoras, indo de 25 a $35 \%$ na ordem citada para as respectivas áreas. ${ }^{6}$ Com relação à produção científica nos países Ibero-americanos, as mulheres são minoria nas publicações na área de Química e Física, nos anos de 2014-2017. Além disso, no âmbito nacional de publicações e citações, as mulheres são autoras de apenas $40 \%$ dos artigos publicados neste período. ${ }^{7}$ Desse modo, a pequena representatividade de pesquisadoras mulheres na área das exatas, e sua baixa representatividade nas 
publicações, leva a uma reflexão a respeito do número ainda menor de mulheres que atingem estágios mais elevados de reconhecimento a nível mundial, como por exemplo, o prêmio Nobel. Ao avaliar a quantidade de mulheres agraciadas com a honraria, verifica-se que dos 904 cientistas premiados, entre 1901 e 2018, apenas 51 (5,6\%) foram mulheres. Para a área da Química, do total de 181 premiados, apenas 5 são mulheres $(2,8 \%){ }^{6}$ Tal fato pode sugerir um reflexo do efeito tesoura, no qual a quantidade de mulheres vai diminuindo à medida que se avança na carreira e é fortemente influenciado pelos estereótipos e pelas próprias funções sociais e culturais da mulher a partir do período em que surgem mudanças significativas na vida pessoal da mulher, como casamento e filhos. Além da produção cientifica e premiações, cientistas também participam das sociedades científicas e agências de fomento e possuem cargos de liderança nestas instituições e dentro da universidade. Esses cargos e funções são muito importantes, pois são decisivos na formulação de políticas públicas, diretrizes e prioridades no financiamento da ciência e normas que ditam de maneira geral as instituições vinculadas à pesquisa.

Portanto, a necessidade de estudos voltados para a problemática de disparidade de gêneros na área científica é de extrema relevância, visto que a discussão de paridade de gênero se tornou uma questão proeminente. Ainda assim, na área de Química têm-se poucos estudos específicos, diferentemente de algumas áreas específicas, como física e matemática as quais vêm se engajando nesta discussão. ${ }^{6,8}$

Desta forma, a motivação deste trabalho foi realizar um levantamento de dados detalhados sobre o panorama da mulher na ciência na área da química no Brasil entre 2018 - 2019 e em alguns casos se referem a um período maior, considerando todos os níveis da carreira acadêmica. Avaliou-se a paridade de gênero dentre (i) bolsistas de iniciação científica (IC); (ii) alunos de pós-graduação e premiações de teses; (iii) bolsistas de pós-doutorado; (iv) docentes na graduação e pós-graduação; (v) bolsistas de produtividade do CNPq nos diversos níveis e membro da Academia Brasileira de Ciências (ABC); (vi) coordenações de projetos aprovados e Institutos Nacionais de Ciência e Tecnologia (INCT); (vii) cargos de reitoras, coordenadoras de graduação e pós-graduação; (viii) posições de liderança como presidentas, e membros consultivo ou da diretoria de sociedades científicas e agências de fomento; (ix) autorias de artigos em revistas de prestígio internacional e nacional; e (x) autorias dentre os artigos mais citados com cientistas brasileiros. A metodologia de levantamento de dados será resumidamente apresentada na sessão "fonte dos dados coletados", no final deste artigo e está mais detalhada no Material Suplementar, juntamente com todas as tabelas. O objetivo geral é apresentar um contexto mais específico com relação a representatividade feminina no Brasil para área de Química e sempre que possível sendo apresentado por região do país. Espera-se que essa divulgação amplie e fortaleça a discussão e as ações para promover as mulheres na ciência e ampare estudos de paridade de gênero.

\section{E AS MULHERES CIENTISTAS NA QUÍMICA BRASILEIRA?}

\section{Formação acadêmica e científica}

A maior parte da pesquisa no Brasil é realizada nas universidades públicas, sendo esse o mais importante veículo na formação acadêmica e científica das cientistas, bem como do desenvolvimento científico do país. De maneira geral, a formação de uma cientista passa pela graduação, algumas vezes com experiência de IC e após segue para a pós-graduação, cursando mestrado e doutorado. Assim, foi de interesse levantar dados dessa trajetória acadêmica, que estão apresentados na Figura $1 \mathrm{em}$ termos da porcentagem de mulheres e também em números absolutos totais (homens e mulheres), por região brasileira.

\section{Estudantes Mullheres}

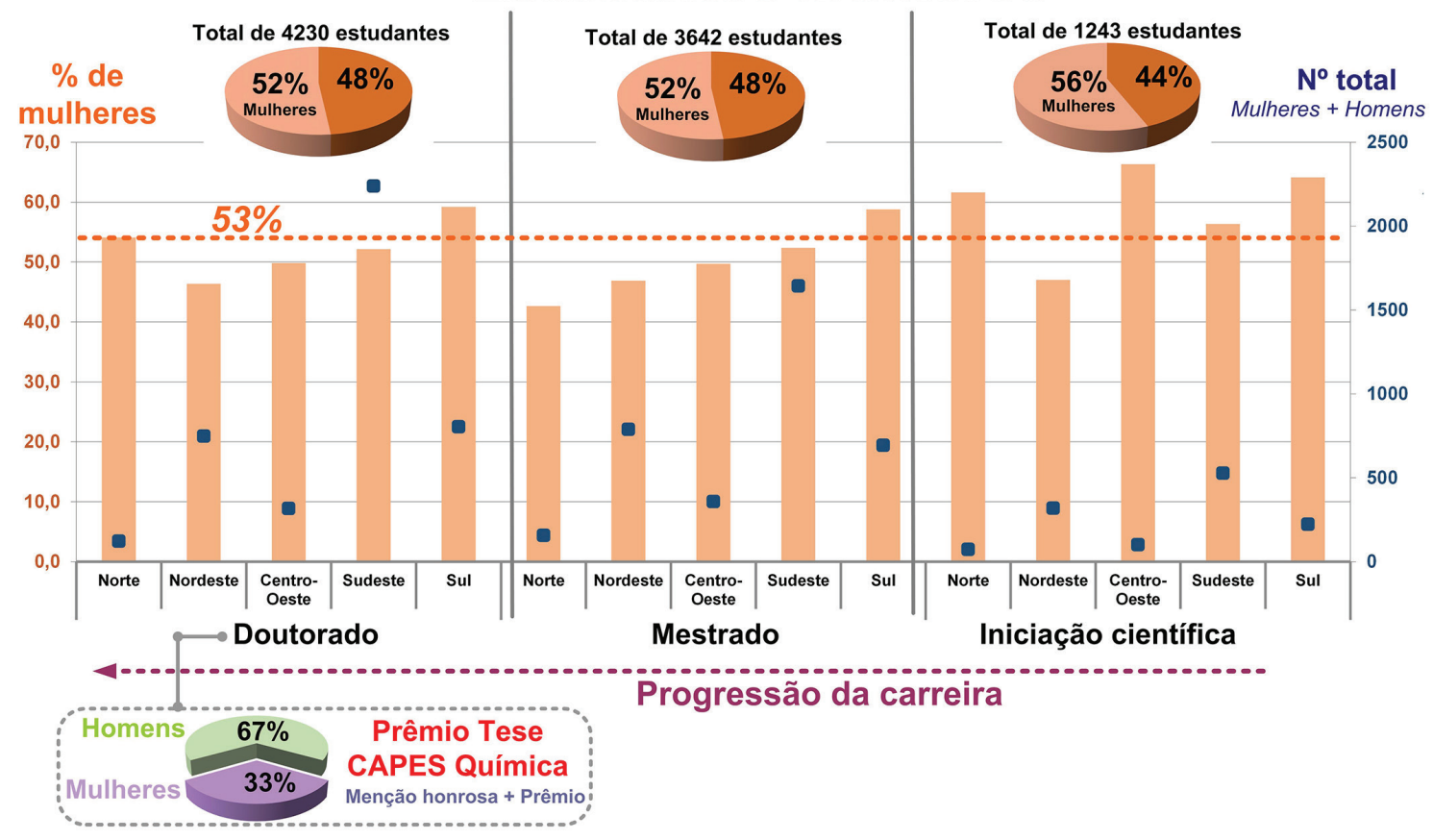

Figura 1. Representação feminina dentre os diferentes níveis de titulação (IC, mestrado e doutorado) e por região brasileira. Os dados estão mostrados como porcentagem de mulheres (eixo à esquerda, gráfico de barras) e números totais de homens e mulheres (eixo à direta, símbolo quadrado) de discentes. Os bolsistas de IC foram obtidos da base de dados do CNP q com bolsa em andamento em 2018. ${ }^{9}$ Para alunos de mestrado e doutorado, os dados foram obtidos da Plataforma Sucupira da CAPES, considerando os discentes titulados e em andamento em 2017. ${ }^{10}$ A porcentagem de mulheres que receberam Prêmio CAPES de tese na área de Química também estão apresentados, sendo considerados dados do site da CAPES no período de 2006 à 2018 , tanto prêmio quanto menções honrosas 
Analisando a Figura 1 no sentido da progressão da carreira, ou seja, iniciando pela IC, observa-se que no Brasil tem-se que 56\% dos bolsistas são mulheres. Observa-se que as regiões Centro-Oeste $(66 \%)$ e Sul $(64 \%)$ se destacam com maior porcentagem, seguida do Norte, Sudeste e Nordeste. Vale ressaltar que o total de bolsistas em números absolutos é menor no Centro-Oeste e Norte, o que pode supervalorizar esses números. De fato, o número total de alunos de IC é maior para região Sudeste, seguida da Nordeste, Sul, Centro-Oeste e Norte. A quantidade de alunos de IC pode estar correlacionada com a quantidade de universidades (universidades federais, estaduais e institutos) que possuem graduação em química e, portanto, podem ser contempladas com bolsa de IC, que é maior para as regiões Nordeste (38 universidades), Sudeste (34 universidades) e Sul (18 universidades) e menor para as regiões Norte (17 universidades) e Centro-Oeste (12 universidades). ${ }^{11}$

Ao progredir na trajetória acadêmica, observa-se que a representação feminina diminui levemente de $56 \%$ de IC para $52 \%$ de pós-graduando (mestrado e doutorado). No mestrado, a ordem de representação feminina dos discentes segue Sul $>$ Sudeste $>$ Centro-Oeste $>$ Nordeste $>$ Norte. Já dentre os discentes de doutorado, tem-se mais mulheres no Sul, seguido do Norte e depois Centro-Oeste, Sudeste e Nordeste. A região Sudeste possui um número total de discentes de doutorado muito acima das outras regiões (2239 discentes), mas apresenta a $4^{\circ}$ posição na representação feminina. De maneira geral a região Sul se destaca com maior porcentagem de mulheres dentre os discentes de mestrado e doutorado. O Norte tem menor número total (homens e mulheres) de discentes tanto no mestrado quanto doutorado, podendo afetar uma correlação adequada.

A Figura 1 deixa claro que da IC para a pós-graduação, a porcentagem de mulheres diminui, mas, mesmo assim, considerando todos discentes (IC, mestrado, doutorado), as mulheres representam um número bastante significativo de 53\% na área de Química. Outra análise interessante apresentada na Figura 1 é referente a posições de destaque durante a progressão da carreira, como por exemplo, o Prêmio CAPES de Tese, uma honraria atribuída para as teses de doutorado mais relevantes de cada ano, dentro das 49 áreas de avaliação reconhecidas pelo MEC. Observa-se que considerando as duas modalidades menção honrosa e Prêmio CAPES Tese (área da Química no período de 2006 a 2018), apenas 33\% dos prêmios foram agraciados a mulheres. Para a menção honrosa, de um total de 18 teses vencedoras, apenas 5 são de mulheres. Enquanto para o Prêmio CAPES de tese, de um total de 9 teses vencedoras, apenas 4 são de mulheres.

\section{Carreira de cientista}

Seguindo a tendência da progressão da carreira de cientista, após concluído o doutorado, muitas assumem posições nas universidades como docentes e pesquisadoras. Dessa forma, avaliou-se a representatividade das mulheres atuantes como docentes, na área de Química, nos cursos graduação e pós-graduação de acordo com cada região do país, ilustrada na Figura 2. De forma geral, é verificado que para os cursos de graduação as mulheres têm uma representatividade de $42 \%$ no quadro de docentes no cenário nacional. De fato, observou-se uma diminuição das mulheres que concluíram pós-graduação (52\%) e estão na posição de docente. Quando se verifica essa distribuição de docentes por região, é visto que as regiões que apresentam maior porcentagem de mulheres docentes na graduação são a Sul e

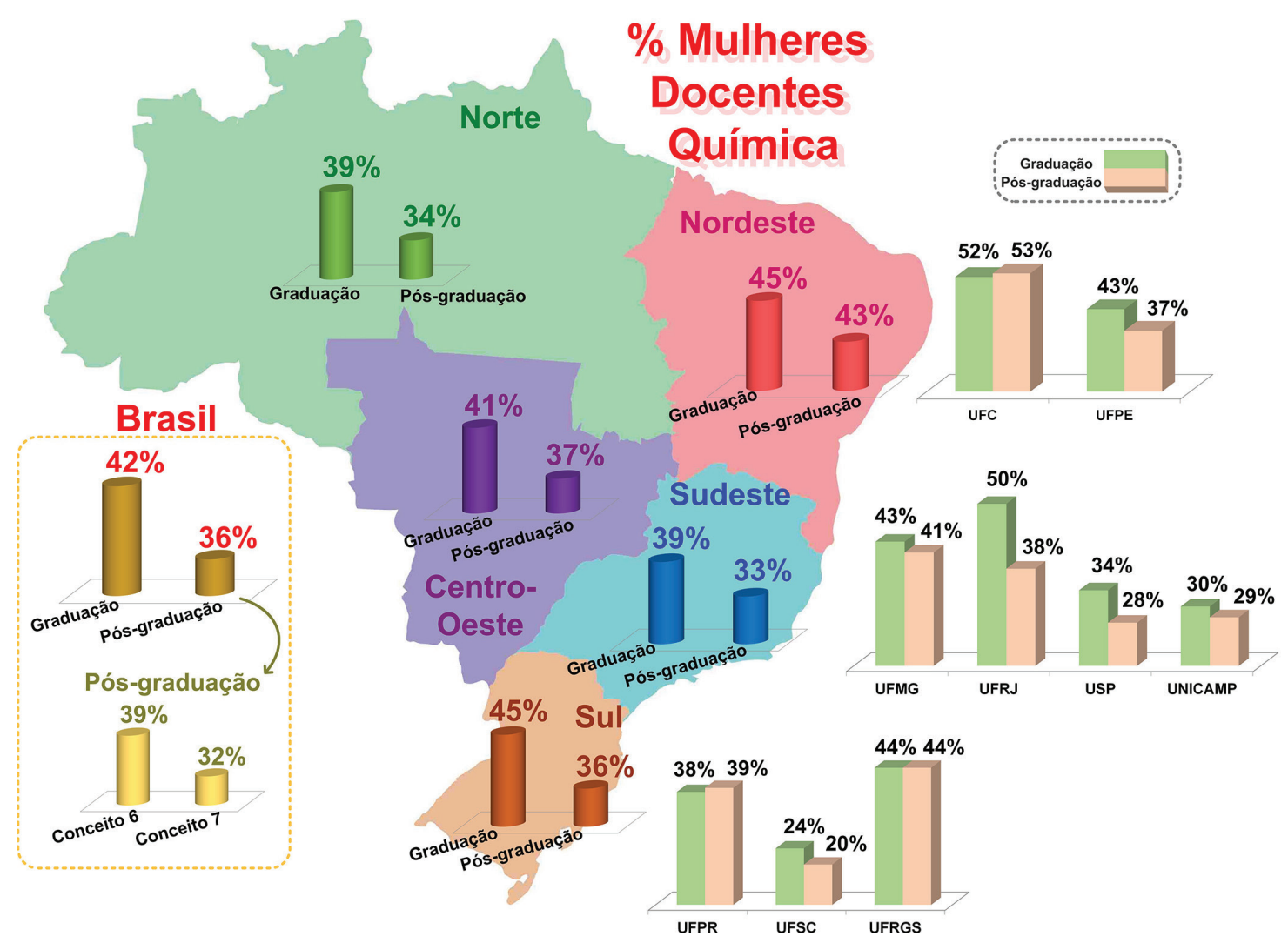

Figura 2. Porcentagem de mulheres docentes, das universidades federais e estaduais, nos cursos de química na graduação e pós-graduação, por região brasileira. Os números de algumas universidades destacadas entre os melhores cursos de graduação e pós-graduação também estão apresentados. Fonte: Para os docentes da graduação de universidades federais, foi utilizado o Portal da Transparência do Governo Federal referente a $2019 .{ }^{12}$ Para as universidades estaduais foi analisada a grade de docentes encontrada no site da instituição referente a 2019. Para os docentes da pós-graduação foi utilizada a plataforma Sucupira considerando a área de Química 2018 
a Nordeste (com 45\%). Já as regiões com menor porcentagem são Sudeste e Norte (com 39\%).

Entretanto, considerando-se a quantidade total de mulheres docentes na graduação no país, verifica-se que na região Sudeste há um maior número absoluto de mulheres docentes, correspondendo a $38 \%$ da totalidade de mulheres do Brasil. Esse dado configura o Sudeste como uma região significativa neste cenário, onde estão situadas várias universidades de destaque nacional e internacional (15 foram analisadas), mas que possui a menor representação feminina de todas as regiões brasileiras. Já para a região Norte, observa-se o oposto, com uma porcentagem de apenas $4,5 \%$ de todas as mulheres docentes do Brasil. Apesar do número de universidades que ofertam o curso de Química no Norte ser menor que no Sudeste (8 universidades analisadas), essa porcentagem ainda é baixa.

A representatividade das mulheres nas melhores universidades do Brasil também é um parâmetro relevante para se analisar, uma vez que estão relacionadas ao alto desenvolvimento científico e tecnológico do país. Assim, algumas universidades de destaque de acordo com vários rankings de avaliação de cursos de graduação, também foram selecionadas (Figura 2). Na região Nordeste destaca-se a UFC e UFPE, onde a UFC apresenta 52\% de mulheres docentes na graduação e a UFPE, $43 \%$. Já no Sudeste, a UFRJ apresenta equidade de mulheres docentes, enquanto UFMG está pouco abaixo com $43 \%$ e após encontra-se a USP e UNICAMP com representação feminina muito menor (34 e $30 \%$, respectivamente). Na região Sul, a UFRGS tem $44 \%$, seguido da UFPR com $38 \%$ e significativamente menor tem-se a UFSC com $24 \%$, sendo essa a menor representação dentre as instituições analisadas. Considerando o ranking Universitário específico da Folha de 2018, ${ }^{13}$ o qual classifica as melhores instituições Brasileiras em um âmbito geral de cursos, tem-se a USP com a melhor avaliação do país, seguido da UFRJ, UFMG e UNICAMP. Com exceção da UFRJ, observa-se que instituições de maior reconhecimento (centros de referência) têm baixa representação feminina.

Outra progressão na carreira de uma cientista é ser credenciada em programas de pós-graduação, visto que nem todos os docentes de cursos de graduação participam da pós-graduação realizando pesquisas e atividades correlatas, dando aulas, bem como orientando alunos. Inclusive um dos primeiros passos para se iniciar na carreira de pesquisador é o seu credenciamento em programas de pós-graduação, que além de ser caminho de permitir consolidar seu grupo de pesquisa, orientando alunos de pós-graduação, muitas vezes é inclusive pré-requisito para editais de fomento.

Em relação aos docentes permanentes credenciados no programa de pós-graduação em Química (Figura 2), a representatividade feminina no panorama nacional é de $36 \%$, indicando a diminuição na porcentagem de mulheres quando comparado às docentes de cursos de graduação. Ao analisar por região, verifica-se que a região com maior representatividade feminina é a Nordeste (43\%), seguida das regiões Sul, Centro-Oeste, Norte, Sudeste. O Sudeste apresenta apenas $33 \%$. Uma comparação entre esses extremos para as regiões Nordeste e Sudeste merece ênfase. Vale ressaltar que é observada uma diferença de $10 \%$ entre estas regiões, sendo que ambas se destacam por apresentar a maior quantidade de programas de pós-graduação do país (22 e 15 programas para Sudeste e Nordeste, respectivamente). Ainda se destaca o número total de docentes credenciados (mulheres + homens) que é maior para a região Sudeste (760 docentes) em contraste ao Nordeste (354), mas que não parecem justificar a menor representação na região Sudeste (33\% mulheres).

Além disso, também foram analisados os programas de pós-graduação com conceito 6 e 7 segundo a avaliação da CAPES, que são de maior prestígio e reconhecimento internacional. Para os programas com conceito 6 , o percentual de mulheres docentes é de $39 \%$ e para conceito 7 é de $32 \%$. Em comparação com todos os programas, isso demonstra um leve aumento na representação para cursos de conceito 6 e uma diminuição para cursos de conceito 7, que são o de maior prestígio.

Avaliou-se o perfil de algumas instituições conceituadas com programas de pós-graduação conceitos 6 e 7 das regiões Nordeste, Sudeste e Sul (Figura 2). Observa-se de maneira geral que a representação feminina como docentes da graduação é maior do que as docentes da pós-graduação nas universidades destacadas, com exceção da UFC e UFPR que apresentam leve aumento e UFRGS que não variou. Dentre as docentes da pós-graduação, destaca-se a UFC com maior porcentagem de mulheres (53\%), seguida da UFRGS (44\%) e UFMG (41\%). As universidades com menor representação são a UFSC (20\%), USP (28\%) e UNICAMP (29\%). Esses números baixos são bastante alarmantes, considerando o reconhecimento nacional e internacional dessas universidades.

Buscando mais informações quanto a carreira da mulher cientista, foi analisado outro parâmetro de grande reconhecimento e prestígio na pesquisa nacional que é a bolsa de produtividade do CNPq que pesquisadores com vínculo formal com instituições de ensino e/ou pesquisa recebem no Brasil. Ela está dividida entre os níveis 1A, 1B, 1C, 1D e 2 que seguem a progressão da carreira, sendo $1 \mathrm{~A}$ e $1 \mathrm{~B}$, considerados por muitos o topo da carreira da cientista no Brasil. Assim, analisou-se a porcentagem de mulheres que recebem bolsa produtividade do $\mathrm{CNPq}$, bem como de bolsas de pós-doutorado (Pós-Doc) que são destinadas a doutores que não possuem cargo de professor universitário efetivo ou qualquer outro vínculo empregatício, todos na área de Química. Na Figura 3 está apresentada a distribuição dos diferentes níveis de bolsa de produtividade e Pós-Doc, de acordo com a região. Diferenças significativas são observadas ao comparar o panorama brasileiro de pesquisadores $1 \mathrm{~A}-2$ e Pós-Doc. O tamanho da bolha laranja presente na Figura 3 está relacionado à quantidade total de pesquisadores (homens + mulheres) por níveis, de forma que se pode observar que quanto maior o nível, menor a quantidade de pesquisadores inseridos em cada nível. Ao verificar a porcentagem de mulheres pesquisadoras em cada nível observa-se que conforme ocorre a progressão na carreira, diminui o número de mulheres. As mulheres Pós-Doc correspondem a 49\% de todos os pesquisadores dessa categoria que é um valor intermediário entre discentes de pós-graduação e docentes na graduação, como esperado. Esses bolsistas Pós-Doc estão mais concentrados na região Sudeste (55\%). Em seguida, analisando os bolsistas de produtividade, tem-se $34 \%$ de mulheres no nível 2. Indo para níveis mais altos, esse número cai sendo que no nível 1D e 1C tem-se $28 \%$ e $31 \%$ de mulheres, respectivamente. Já para estágios mais altos da carreira como nível $1 \mathrm{~B}$, esse número cai para $21 \%$, que corresponde a 12 pesquisadoras no Brasil todo. Por fim e muito assustador, tem-se apenas $12 \%$ de mulheres no nível 1A, representando apenas 7 mulheres no cenário nacional (de todos 61 bolsistas mulheres e homens). Esses números têm um impacto muito grande visto que em geral são pesquisadores 1A e 1B que compõem comitês de assessoramento das agências de fomento e participam na formulação de políticas públicas. Portanto, seu status garante posições de grande influência na ciência brasileira que ainda tem uma representação feminina baixíssima. Isso se traduz em posições de liderança, prestígio e reconhecimento, que por sua vez se tornam referências para o restante da sociedade (onde estão as mulheres cientistas?).

Foi analisado individualmente cada nível de bolsista produtividade, considerando como variável a região, como pode ser visto na Figura 3 no gráfico de pizza. Em todos os níveis tem-se uma maior porcentagem de pesquisadoras mulheres na região Sudeste. No nível 2, tem-se 53\% no Sudeste, seguido de $22 \%$ no Nordeste, seguido do Sul, Centro-Oeste e Norte. No nível 1D não se tem representantes na região do Norte e Centro-Oeste, tendo uma distribuição de 54, 25 e 21\% para Sudeste, Sul e Nordeste, respectivamente. Um 
comportamento similar é observado para nível 1B. No nível 1C, tem-se $74 \%$ no Sudeste, $16 \%$ no Nordeste e $10 \%$ no Sul. Por fim, no nível $1 \mathrm{~A}$, todas as pesquisadoras estão concentradas no Sudeste. Mesmo assim, isso representa poucas mulheres, correspondendo a 7 mulheres num total de 41 pesquisadores da região Sudeste. Outra análise interessante é que os $8 \%$ das mulheres no nível 1B na região Nordeste, corresponde a apenas 1 mulher. Na região Norte, as bolsistas nível 2 correspondem a um total de $0,7 \%$ condizendo a apenas 1 pesquisadora num total de 140 pesquisadoras mulheres no país.

Outro fator que deve ser observado é a relação entre a representatividade feminina de pesquisadoras Pós-Doc e pesquisadoras com bolsa de produtividade CNPq. Verifica-se que existe uma discrepância de aproximadamente $14 \%$ entre as mulheres inseridas como bolsa de Pós-Doc e o primeiro nível da carreira de pesquisador do $\mathrm{CNPq}$ (Nível 2). Este número é significativo, visto que para ambos os níveis a quantidade total de pesquisadores (mulheres + homens) é praticamente equivalente (Pós-Doc número total de 371 pesquisadores e Nível 2 do CNPq total de 413 pesquisadores). Para os demais níveis do $\mathrm{CNPq}$ a diferença é ainda maior ao comparar o elevado número de mulheres Pós-Doc (181 mulheres x 190 homens) e os níveis: 1A ( 7 mulheres x 54 homens), 1B (12 mulheres x 45 homens), 1C (19 mulheres $x 42$ homens), $1 \mathrm{D}$ ( 28 mulheres $x 74$ homens) e 2 ( 140 mulheres x 273 homens). Esse quadro é alarmante, considerando que o período de Pós-Doc se trata de um estágio como pesquisador sem vínculo empregatício, e só apenas nos outros níveis é que o profissional está inserido formalmente no mercado de trabalho.

Sabe-se que uma das maiores honrarias da carreira de pesquisador brasileiro é ser nomeado como membro da $\mathrm{ABC}$ e, dessa forma, é imprescindível considerar o cenário de representatividade de gênero nesta instituição. Quando analisados os membros titulares desta academia (Figura 3), é verificada na área de Química a presença de apenas $19 \%$ de mulheres. Esse valor equivale a apenas 12 mulheres de um total de 63 membros. Além disso, cronologicamente, a primeira mulher nomeada membro titular foi em 1977, 60 anos depois da fundação da ABC (em 1916). Observando os dados por região verifica-se que todas as 12 pesquisadoras estão concentradas na região Sudeste e 58\% delas estão no estado de São Paulo, indicando a necessidade de maior representatividade regional e feminina. ${ }^{14}$

Uma correlação interessante é que, ainda que a região Sudeste tenha em números absolutos, maior quantidade de discentes de doutorado, tem uma das menores representações femininas nessa classe. Analogamente, as mulheres docentes na graduação na região Sudeste estão entre os menores índices do país e tem menor porcentagem de docentes mulheres na pós-graduação no Brasil, próximo a 33\%. Ou seja, tem-se um número pequeno de pesquisadoras no Sudeste, mas que conseguem alcançar posições de maior prestígio na carreira (i.e., membro da $\mathrm{ABC}$, bolsistas produtividade). Essa disparidade de gênero por região é igualmente preocupante porque dita padrões de referências e lideranças femininas que poderá por um lado inspirar ou por outro, desestimular futuras gerações. Juntamente com a preocupação em promover a paridade de gênero, devem-se concentrar esforços para que isso seja feito nas diversas regiões, principalmente num país como o Brasil, de dimensões continentais. De fato, essa análise por região é complexa pois também se sabe que muitas posições de liderança e reconhecimento científico no Brasil concentram-se na região Sudeste (homens + mulheres). Por outro lado, isso também é reflexo de anos de investimento público por fundações estaduais de fomento à pesquisa (e.g. FAPESP).

\section{Carreira de pesquisadora}

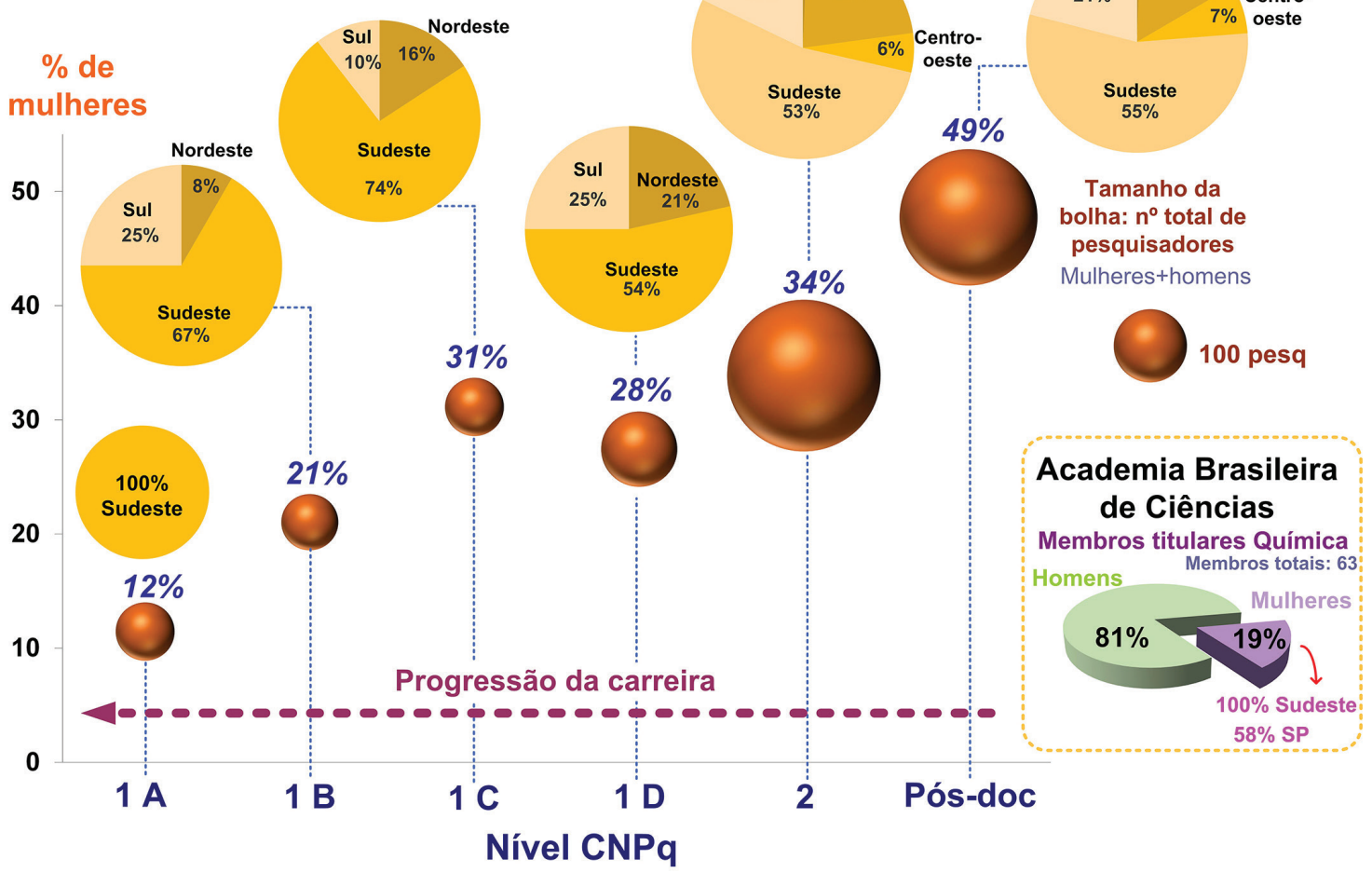

Figura 3. Distribuição de gênero na progressão da carreira científica de uma pesquisadora desde o nível Pós-Doc, bolsista produtividade do CNPq (níveis $1 A, 1 B, 1 C, 1 D$ e 2) até a titularidade na ABC, por região brasileira. Dados apresentados como porcentagem de mulheres e o tamanho da bolha corresponde ao número total de pesquisadores (mulheres e homens). Fonte: Os dados referentes às bolsas produtividade foram obtidos no site do CNPq (ano base 2018$)^{7}$ enquanto que os dados de pesquisadores Pós-doc foram obtidos na plataforma sucupira (ano base 2019). ${ }^{10}$ Em relação aos membros titulares da ABC, os dados foram obtidos em seu site oficial em 06/201914 
O sucesso da carreira de uma cientista também depende fortemente dos seus projetos de pesquisa aprovados. Nesse sentido, o CNPq tem sido um órgão de fomento brasileiro fundamental e um dos seus editais mais tradicionais é o Universal. Durante anos, tem-se aberto editais para essa chamada que apresenta três modalidades de acordo com a faixa máxima de financiamento, no qual a faixa $\mathrm{A}$ vai até $\mathrm{R} \$ 30.000,00$, faixa $\mathrm{B}$ até $\mathrm{R} \$ 60.000,00$ e faixa $\mathrm{C}$ até $\mathrm{R} \$ 150.000,00$. Em geral, o perfil que se observa é que a faixa $\mathrm{A}$ é voltada para jovens pesquisadores, enquanto a faixa $\mathrm{B}$ para cientistas num ponto mais intermediário da carreira. Já a faixa $\mathrm{C}$ é para cientistas mais no topo na carreira, geralmente envolvendo pesquisadores bolsista produtividade do CNPq (nível 1A a 1C). Na Figura 4 é representada a liderança feminina em Projetos Universais (2007 a 2018). Ao longo dos anos, é possível verificar que em média a quantidade de projetos aprovados por mulheres é pequena, mas é maior na faixa A (35\%), seguido da faixa B $(27 \%)$ e da faixa C (21\%). A faixa A apresenta o maior número de projetos aprovados, seguida da B e C. Contudo, é evidente a discrepância entre o número de mulheres e homens favorecidos em cada faixa. Para todas as faixas e para todos os anos, a porcentagem de mulheres que alcançam um financiamento para projeto pelo Universal não se aproxima da equiparação, independente da faixa. E considerando que não há, ao decorrer dos anos, uma mudança neste perfil para um progresso em relação ao maior percentual de mulheres prestigiadas, torna-se uma situação alarmante. Isso é extremamente relevante considerando que se trata de um dos editais de financiamento mais importantes do país. Além disso, considerando que para a faixa $\mathrm{C}$ são contemplados apenas os pesquisadores com maior prestígio, a baixa representatividade feminina ilustra de novo um efeito tesoura das mulheres ao subir na carreira.

Ao analisar os números absolutos, é verificado que a quantidade de mulheres contempladas com o financiamento é pequena ao longo dos anos. Os dados ao longo dos anos não se apresentam de forma linear (crescente ou decrescente) e devido a isso analisamos alguns extremos, como por exemplo: para a faixa B é verificado que em 2008, dos 40 projetos aprovados apenas 8 destes foram destinados às mulheres. Para a faixa A é observado algo similar no ano de 2018 no qual para um total de 89 projetos apenas 21 foram destinados para mulheres pesquisadoras. Além disso, também são observados extremos dentro de cada faixa no decorrer dos anos. Para a faixa $\mathrm{C}$, mais difícil de aprovar, no ano de 2018 foi verificado o maior número de projetos desta categoria, totalizando 48 projetos aprovados sendo apenas 10 para mulheres. Contudo no ano de 2010 é observado o menor número de projetos contemplados, um total de 17 , do qual apenas 3 foram para mulheres. Para a faixa $\mathrm{B}, \mathrm{o}$ ano de maior número de projetos aprovados foi 2018, com um total de 122 projetos dos quais 36 foram atribuidos para mulheres. Em contrapartida, em 2011 foi o ano com menor número de projetos atribuidos, 36 ao total sendo 9 para mulheres. Na faixa A, o ano de 2014 foi o que destacou-se com maior número de projetos aprovados, total de 135 dos quais 49 foram para mulheres, e o ano de 2011 foi o que apresentou menor número de projetos aprovados, total de 82 dos quais 27 foram para mulheres. Assim, observa-se que o ano de 2018 foi um dos que mais teve projetos aprovados na faixa $\mathrm{B}$ e $\mathrm{C}$, mas isso não reflete um maior investimento, visto que foi um ano com grandes cortes no orçamento brasileiro de ciência e tecnologia, ainda que não seja objeto de discussão no presente trabalho.

De maneira geral, é evidente a baixa representatividade feminina na liderança de projetos Universal e como a tendência não variou num intervalo de 10 anos (Figura 4). A aprovação de projetos Universal é considerada uma posição de prestígio e reconhecimento no Brasil que tem grande concorrência, até mesmo na faixa A, de menor financiamento. Ou seja, posições cada vez mais importantes na ciência brasileira tem baixa representação feminina.

Além dos editais do CNPq direcionados ao pesquisador individual, o CNPq tem parceria com o Programa Institutos Nacionais de Ciência e Tecnologia (INCT), juntamente com CAPES, FAPs (fundação de amparo à pesquisa dos estados), por meio da formação de redes de pesquisa que abrangem todas as áreas com o caráter de contribuir com pesquisa em ciência e tecnologia em temas estratégicos para o país. Destacamos na Figura 4 a representatividade de homens e mulheres na coordenação dos INCTs na última chamada (16/2014) que está vigente em 2019. A liderança de INCTs também é considerada uma posição de grande importância na carreira de um cientista brasileiro, visto que são redes com financiamento massivo e

\section{Projetos Universal Aprovados por Mulheres}

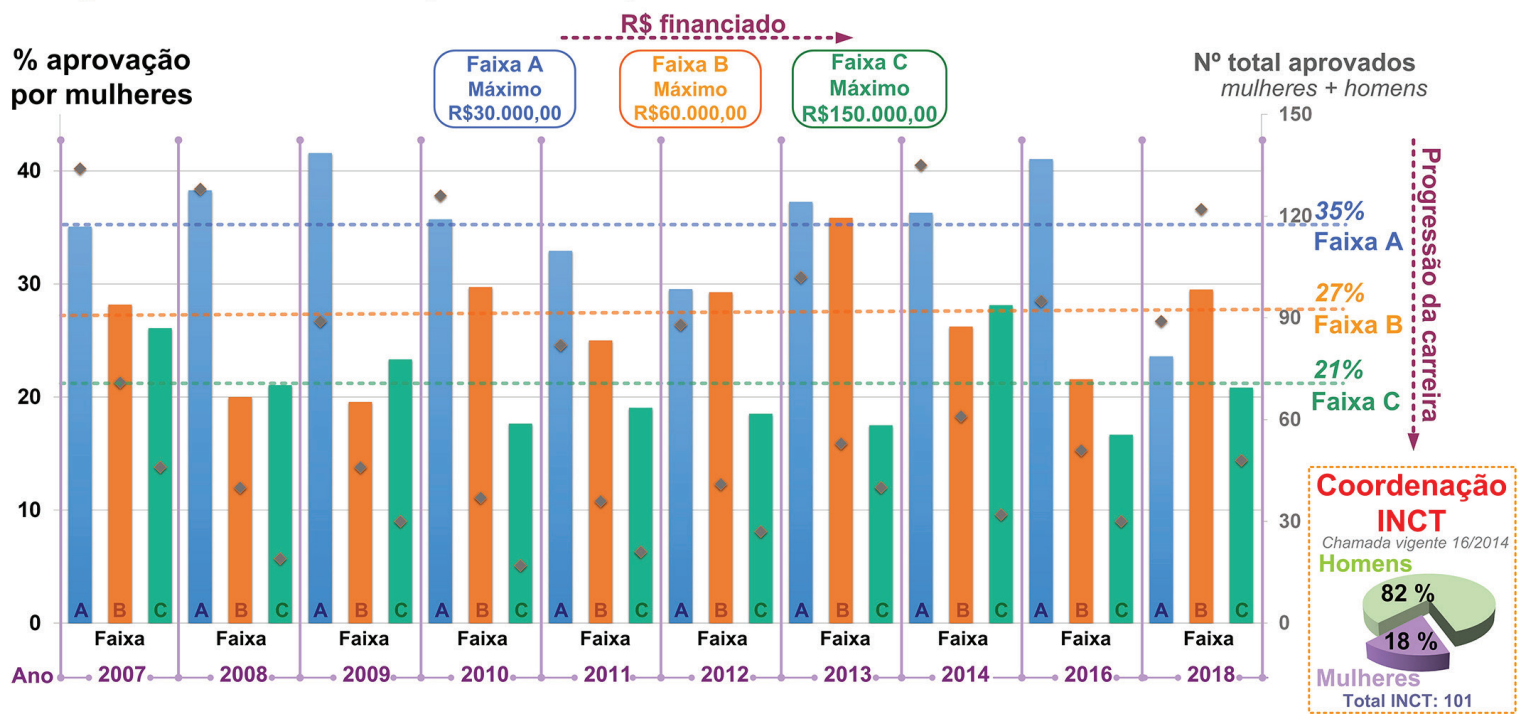

Figura 4. Liderança feminina em na aprovação de projetos Universal do CNPq na área de Química entre 2007-2018 nas faixas A, B e C. A representação feminina na coordenação de INCTs está mostrada, referente ao último edital aprovado (2014), que está vigente em 10/2019. Fonte: Os dados dos projetos aprovados (Universal e INCTs) foram obtidos nos resultados dos editais, disponíveis no site do CNPq 
de grande impacto nos avanços científicos do país. Foram consideradas todas as áreas contempladas com 101 projetos aprovados, sendo possível verificar que a representatividade feminina é de apenas $18 \%$ dentre os coordenadores.

Os números mostrados na aprovação de projetos Universal e de INCTs concordam com a tendência que ocorre com a progressão da carreira. De fato, as mulheres que conseguem bolsa produtividade 1B e $1 \mathrm{~A}$ representam 21 e $12 \%$ de todos bolsistas, enquanto na ABC tem-se apenas $19 \%$ membros titulares mulheres na área de química. A aprovação de projetos Universal na faixa C por mulheres é $21 \%$, enquanto na coordenação de INCTs é $18 \%$. Por que as mulheres não conseguem ter maior representação nesses estágios mais avançados da carreira? Elas não têm mérito e não fazem uma boa ciência ou existem realmente empecilhos e falta de oportunidades? Certamente o Brasil tem grandes cientistas que merecem reconhecimento e oportunidade para assumir cargos de liderança e participar de decisões estratégicas para a ciência brasileira.

\section{Representatividade feminina em cargos de lideranças}

Ao tratar de lideranças científicas, diversas são as formas de estas estarem distribuídas nas universidades, sociedades científicas e órgãos de fomento. Assim, existem as coordenações de cursos de graduação, PPG, reitorias, presidência e membros de diretoria ou conselhos consultivos/deliberativos de sociedades científicas ou agências de fomento. Essas representações exercem um papel fundamental nas delegações de atribuições, prioridades, recursos e reconhecimento científico nacional. Certamente a representatividade feminina nessas esferas é fundamental, pois cria referências que toda comunidade científica irá se inspirar, espelhar e motivar para seguir em suas carreiras. Essas referências muitas vezes acabam determinando estereótipos e preconceitos do perfil de um(a) cientista. Por outro lado, poucas referências femininas científicas e líderes também criam maiores barreiras para que futuras gerações de mulheres persistam na área científica ou almejem cargos de liderança.

A Figura 5 apresenta a distribuição das mulheres liderando algumas posições de coordenação na universidade (graduação, PPG e reitoria). Quando analisadas as posições de coordenação dos cursos de graduação e PPG em química, a média nacional de coordenadoras de graduação é maior do que a média nacional de coordenadoras da pós-graduação: $42 \%$ versus $32 \%$. Em relação à coordenação da graduação (licenciatura e bacharelado) por região, a região Sul apresenta mais mulheres como coordenadoras (54\%), seguida da região Sudeste $(44,6 \%)>$ Centro-Oeste $(44,4 \%)>$ Norte $(33,3 \%)>$ Nordeste (32\%). Ao analisar a coordenação de PPG, a região Sul tem a maior quantidade de coordenadoras (50\%), seguida da região Sudeste (30\%), Centro-Oeste (28\%), Nordeste (23\%) e Norte (0\%). Para a região Sul tem-se $50 \%$ de mulheres nas coordenações da PPG, de um total de 14 PPGs. Essa equidade de gênero na coordenação de PPG na região Sul contrasta fortemente com a ausência de coordenadoras mulheres na região Norte, na qual dos 5 programas de PPG nenhum deles é coordenado por mulheres.

Quando comparados os números de coordenadoras com porcentagem das docentes credenciadas nesses programas, algumas
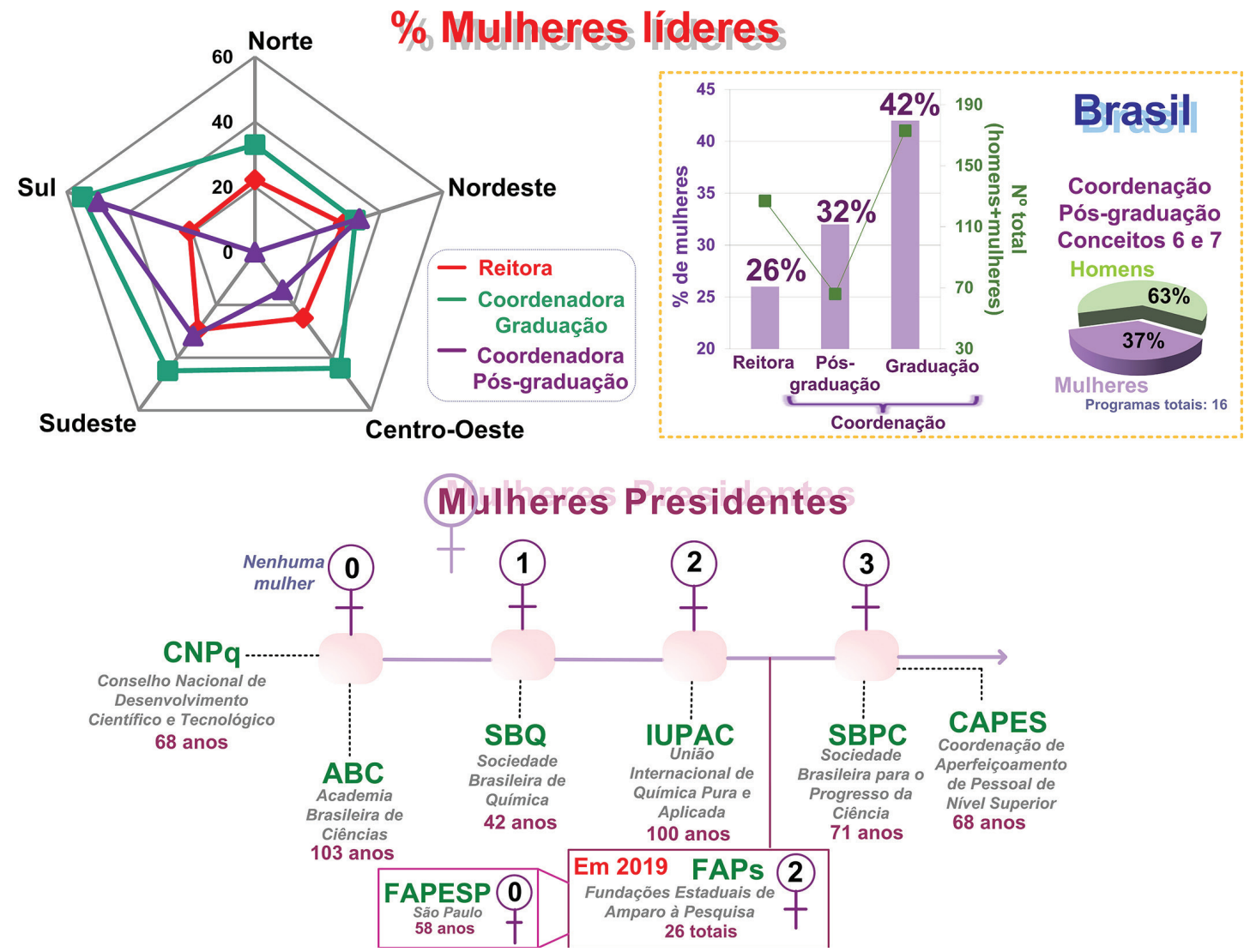

Figura 5. Porcentagem de mulheres ocupando posições de liderança em cargos administrativos em universidades e cargos de presidência em Sociedades Nacionais e Internacionais. Para os cargos administrativos os dados de presidência foram obtidos dos respectivos sites oficiais das instituições citadas, tomando como base o período da fundação até o momento ano 2019.7.14-19 Para esses cargos de presidência foi desconsiderado o número repetido de vezes em que algumas delas foram presidentas por mais de uma gestão a fim de contabilizar números absolutos de mulheres. Os dados de coordenação de pós-graduação foram obtidos da Plataforma Sucupira (busca em 05/2019, ano base 2018). Para a coordenação de graduação e reitoria utilizou-se o site do MEC (busca em 03/2019, ano base 2019) $)^{11}$ 
correlações são interessantes. Vale ressaltar que o número total de docentes é maior que o número total de coordenadores, portanto a porcentagem em alguns casos é mais significativa que em outros. A região Sul possui $36 \%$ de mulheres docentes credenciadas nas PPGs (Figura 2), e tem 50\% dos cargos de coordenador ocupados. Em contraste, na região Norte o número de mulheres credenciadas é bastante similar (34\%, Figura 2), entretanto, não verificamos sua representatividade no cargo de coordenação (0\%). Além disso, outros dois extremos são observados na região Sudeste e Norte. Apesar de a região Sudeste ser a segunda mais representada por mulheres na coordenação de PPG, apresentando um valor de 30\% (7 coordenadoras de 23 cursos de PPG), quando se trata de docentes credenciados, essa região decai para a região menos representada com docentes mulheres (33\%). O inverso ocorre com a região Nordeste, que possui maior quantidade de mulheres credenciadas em PPG (42\%), entretanto, quando se trata de número da coordenação é a região com menor número de mulheres $(23 \%)$.

Nos PPGs de maior prestígio com conceito CAPES 6 e 7, os quais representam um total de 16 programas, a média de incidência de mulheres coordenadoras é de $37 \%$. Isso mostra a tendência da baixa representatividade de mulheres nos programas mais conceituados.

Outro papel de liderança analisado foi a reitoria, que não se restringe apenas à área da Química, mas que igualmente tem uma importância na discussão de lideranças científicas. Analisando um total de 91 reitores, apenas $26 \%$ são mulheres, um número pouco expressivo considerando a importância do cargo. A região Centro-Oeste é a que possui maior número de mulheres no cargo de reitoras $(42,8 \%)$, seguida da região Sudeste (38\%), Nordeste (32\%), Norte (16\%) e Sul, com $11 \%$ de mulheres reitoras, o menor número dentre as regiões.

A Figura 5 também ilustra a representatividade feminina em posições de liderança em sociedades científicas e órgãos de fomento. Vale ressaltar que no Brasil o desenvolvimento da pesquisa científica foi fortemente amparado pela criação dessas agências. Um breve relato histórico de algumas das instituições chaves no progresso científico brasileiro, obtidos através das informações fornecidas nas páginas oficiais de cada uma delas, mostra que o início se dá com a $\mathrm{ABC}$, que existe desde 1916, tendo 103 anos de atuação. ${ }^{14}$ Ser membro titular da $\mathrm{ABC}$ pode ser considerado o topo da carreira de qualquer cientista no Brasil e é uma das posições de maior prestígio. Em 1948, foi criada a Sociedade Brasileira para o Progresso da Ciência (SBPC), que foi estratégica e fundamental na consolidação da soberania brasileira na ciência mundial. ${ }^{10}$

Em 1951, foram criadas pelo Governo Federal duas organizações que têm sua importância destacada até os dias de hoje, e que foram fundamentais para que o país pudesse se desenvolver cientificamente. São elas: CNPq e a CAPES. O CNPq foi criado com o objetivo de promover o desenvolvimento científico e tecnológico no Brasil, além da formação de recursos humanos para esse fim. Sendo assim, possui a finalidade de examinar, avaliar e selecionar os pedidos de projetos de pesquisa de todo o país. ${ }^{7}$ Já a CAPES, tem um papel mais vinculado à avaliação do sistema nacional da pós-graduação e dessa forma fortalecendo e garantindo sua qualidade. Além disso, atua fomentando a formação inicial e continuada de professores para a educação básica. ${ }^{8}$ Outra sociedade de relevância para a área da química nacional foi a Sociedade Brasileira de Química (SBQ), fundada em 1977, no papel de uma organização em oposição ao regime militar e fortalecimento da química no país. ${ }^{19}$ Além dessas sociedades e agências apontadas, outras são citadas na Figura 5 como a União Internacional da Química Pura e Aplicada (IUPAC), e as FAPs. ${ }^{16,19}$ A IUPAC foi criada em 1919, é a mais importante organização científica a nível mundial na área da química. Ela possui a competência em relação à nomenclatura dos elementos e moléculas, bem como padronização de métodos de medida e simbologia, entre outras. Já as FAPs atuam mais localmente no amparo à pesquisa, são fundações estaduais.

Quando se observam os dados referentes a essas sociedades científicas, apresentados na Figura 5, nota-se o baixo número de mulheres em relação ao número de homens que alcançam o cargo de presidência. Isto também é observado para a IUPAC e as FAPs. Esses dados foram obtidos ao analisar as informações disponíveis nos sites oficiais dessas sociedades e agências em todo o seu período de existência, e foi considerada a quantidade de mulheres presidentas neste período sem considerar a quantidade de vezes que repetiram o cargo. Para a ABC, a primeira das sociedades científicas brasileiras, percebemos que nos seus 103 anos de existência nenhuma mulher foi eleita presidenta da entidade. Foi somente em 1991 que uma mulher assumiu um cargo de diretoria, Johanna Döbereiner, como primeira-secretária. O mesmo se repete com o CNPq, que em 68 anos de existência não teve nenhuma mulher presidenta. A SBQ ao longo dos 42 anos teve uma mulher presidenta e a IUPAC teve duas mulheres, ao longo dos 100 anos. Já considerando as 26 FAPs analisadas, em 2019 apenas duas tem mulheres como diretora/presidenta. A SBPC durante os 71 anos, teve 3 mulheres presidentas, mas como algumas repetiram seu mandato, totalizaram, portanto, 6 mandatos. Por fim, a CAPES com 68 anos também teve apenas 3 mulheres presidentas, em 5 mandatos diferentes.

Já na Tabela 1 são apresentadas informações sobre os cargos de presidência e vice-presidência, considerando as repetições da pessoa por cargo (mandatos), e dados das composições dos conselhos e diretorias dessas sociedades. Assim, é possível ter uma visão mais geral da representação feminina nos cargos de diretoria dessas instituições. São mostrados ainda os números de pessoas por mandato, assim contempla mulheres que assumiram cargos mais de uma vez.

Na Tabela 1, também são apresentados os dados relativos à SBPC. Em 71 anos de existência, houveram 35 gestões, sendo apenas 6 vezes o cargo de presidente ocupado por mulheres. A primeira a ocupar esse cargo foi Carolina M. Bori, em 1987, 39 anos depois da sua fundação. Dentro dessa importante sociedade o Conselho é um órgão de alto poder decisório, que em 2019 possuía 11 mulheres num total de 27 membros que o constitui. ${ }^{10}$ Quando olhamos para a composição de diretorias e cargos de relevância nas instituições CNPq e CAPES, notamos também um cenário bastante inexpressivo para as mulheres. Segundo dados disponíveis no site oficial do CNPq, onde constam diretorias de 1951 até a gestão atual, dentre todos os presidentes não houve nenhuma mulher. Até o momento somente duas mulheres foram vice-presidentas, sendo a primeira delas: Alice Rangel de Paiva Abreu no ano 2000. Os dados apresentados na Tabela 1 mostram que de um total de 1407 cargos de dirigentes, apenas 128 (9,0\%) foram ocupados por mulheres. Ainda menos representativos são os números para a quantidade de mulheres que fizeram parte do Conselho Deliberativo: de 1470 cargos apenas $50(3,4 \%)$ foram ocupados por mulheres.

É importante também olhar os dados do cenário para as mulheres nos Comitês de Assessoramento (CAs). Para a área da química é de interesse em particular a Coordenação do Programa de Pesquisa em Ciências Químicas e Geociências (COCQG) que em 2019 era composto por 12 profissionais, sendo 5 mulheres entre eles. ${ }^{7}$

Essa pouca expressividade no número de mulheres em cargos de prestígio também pode ser observada na CAPES. Ao longo de sua existência, houveram 24 gestões, sendo apenas 5 vezes o cargo de presidente ocupado pelo sexo feminino. No caso da CAPES é importante olhar também os dados para o Conselho Superior que é o órgão deliberativo, sendo em 2019 composto de 13 pessoas, em que 3 são mulheres. ${ }^{8}$ Outra importante sociedade citada nesse trabalho, a SBQ, também teve ao longo de seus 42 anos de história de um total de 22 gestões, apenas uma mulher ocupou o cargo de presidente. Somente no seu $17^{\circ}$ mandato (2008), Vanderlan da Silva Bolzani 
Tabela 1. Valores absolutos totais (homens e mulheres), absoluto de mulheres e porcentagem de mulheres dirigentes da $\mathrm{ABC}$, SPBC, CNPq, CAPES e $\mathrm{SBQ}^{\mathrm{a}}$

\begin{tabular}{|c|c|c|c|}
\hline \multicolumn{4}{|l|}{ ABC (1916-2019) } \\
\hline & Total & Mulheres & $\%$ \\
\hline Presidente & 48 & 0 & 0 \\
\hline Vice-presidente & 89 & 2 & 2,2 \\
\hline Diretoria ( secretários, tesoureiros e diretores) & 204 & 4 & 1,96 \\
\hline \multicolumn{4}{|l|}{ SBPC (1948-2019) } \\
\hline Presidente & 35 & 6 & 17 \\
\hline Vice-presidente & 60 & 17 & 28,3 \\
\hline Diretoria (tesoureiros e secretários) & 174 & 53 & 30,4 \\
\hline \multicolumn{4}{|l|}{ CNPq (1951-2019) ${ }^{\mathrm{a}}$} \\
\hline Presidente & 64 & 0 & 0 \\
\hline Vice-presidente ${ }^{\mathrm{b}}$ & 47 & 7 & 15 \\
\hline Diretoria $^{\mathrm{c}}$ & 1407 & 128 & 9 \\
\hline Conselho & 1470 & 50 & 3,4 \\
\hline $\begin{array}{l}\text { Comitê Assessor (COCGQ - dados somente } \\
\text { de 2019) }\end{array}$ & 12 & 5 & 42 \\
\hline \multicolumn{4}{|l|}{ CAPES (1951-2019) } \\
\hline Presidente & 24 & 5 & 21 \\
\hline $\begin{array}{l}\text { Conselho Superior (considerados os mem- } \\
\text { bros natos e representantes da comunidade } \\
\text { acadêmica - 2019) }\end{array}$ & 13 & 3 & 23 \\
\hline \multicolumn{4}{|l|}{ SBQ (1977-2019) } \\
\hline Presidente & 22 & 1 & 4,54 \\
\hline Vice-presidente $^{\mathrm{d}}$ & 21 & 6 & 28 \\
\hline $\begin{array}{l}\text { Diretoria (considerados os tesoureiros e se- } \\
\text { cretários) }\end{array}$ & 86 & 20 & 23 \\
\hline Conselho (consultivo e fiscal titular e suplente) & 156 & 29 & 19 \\
\hline
\end{tabular}

*Dados obtidos nos sites oficiais de cada instituição considerado todo o seu período de existência e considerando mandatos. ${ }^{7,8,10,14,19}$ Para a obtenção dos dados desta tabela, foi considerado o sexo feminino ou masculino por cargo. a Os dados foram obtidos de 1951-2013 e 2019, a lacuna de anos é devido a

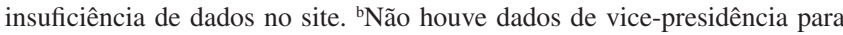
os anos de 1975, 1983-86, 1991-99, 2013 e 2019. 'Foram desconsideradas as pessoas que ocuparam mais de um cargo na mesma gestão. ${ }^{\text {Não houve }}$ vice-presidência na primeira gestão.

assumiu como presidenta da instituição. ${ }^{19}$ Entre os vice-presidentes, do total de 21 gestões, 6 (30\%) vezes o cargo foi ocupado por mulheres. Entre seus cargos de diretoria essa porcentagem cai para um valor aproximado de $23 \%$, o que não é muito diferente dos cargos ocupados no Conselho, que se aproximam de $19 \%$ de mulheres.

Os números apresentados indicam a baixa representatividade feminina em posições de lideranças em sociedades científicas, que é bastante restrita ao longo dos anos. A presença de mulheres nestes conselhos e presidências é de fundamental importância, uma vez que estes influenciam diretamente na eleição de novos membros, amparam a pesquisa Brasileira por meio de aprovações de projetos de pesquisa, direcionamento de recursos para a realização da ciência no país e definem posições de prestígio científico.

\section{Autoria de artigos por mulheres}

A produção científica no Brasil é realizada, majoritariamente, nas universidades públicas, tornando o país, atualmente, o $13^{\circ}$ maior produtor de publicações de pesquisa mundialmente. ${ }^{20}$ De fato, publicações científicas são indicadores importantes na carreira de uma cientista. Assim, buscou-se analisar representatividade de mulheres em publicações em periódicos internacionais na área de química. Para isso, foram escolhidas algumas revistas de prestígio internacional, caracterizadas como interdisciplinares e de editoras diferentes e com significativo índice de impacto. Não foi intuito levantar cenário completo das publicações em cada área da química, mas sim dar um panorama em revistas que são reconhecidas internacionalmente (e nacionalmente) e que publicam artigos nas diferentes áreas da química. A Figura 6 apresenta os artigos publicados nessas revistas que continham autoria com vínculo brasileiro (2016-2018) dados em função da porcentagem de mulheres como primeira autora, última autora, outra autora e nenhuma mulher brasileira na autoria. Uma observação bastante alarmante é que a porcentagem de artigos nos quais a participação feminina é nula é $59 \%$ em média para todas as revistas selecionadas. Isso representa mais da metade dos artigos analisados (100 artigos). Observa-se que a porcentagem de artigos com nenhuma mulher na autoria aumenta para revistas de maior índice de impacto. Por exemplo, dentre as revistas selecionadas, a "Chemistry - A European Journal" com índice de impacto 5,16 tem $54 \%$ dos artigos com nenhuma mulher brasileira na autoria, enquanto as revistas de maior índice de impacto (>20), como "Accounts of Chemical Research", "Chemical Society Reviews" e "Chemical Reviews", essa porcentagem chega a 75\%. Vale ressaltar que essas últimas revistas têm menor número de artigos no total (20 artigos; $12 \%$ do total analisado) por ter caráter de revisão. No entanto, os artigos de revisão normalmente são vinculados a cientistas de grande prestígio de uma determinada especialidade, portanto a baixa representatividade feminina nesses casos também reflete o efeito tesoura em posições de maior reconhecimento.

Analisou-se também a porcentagem de mulheres como última autora dos artigos, sendo considerado uma posição de destaque em uma publicação, pois geralmente refere-se a quem submeteu o artigo e supervisou maior parte daquele trabalho. Observa-se que na média de todas as revistas, somente $3 \%$ dos últimos autores são mulheres (apenas 5 artigos dos 171 totais). Esse número não varia significativamente dentre as revistas de diferentes índices de impacto, exceto para "Chemical Society Reviews" e "Chemical Reviews" que possuem alto índice de impacto, em que a porcentagem de mulher como última autora aumenta, mas como o número de artigos é baixo (3 artigos de 16 totais), esse aumento pode não ser tão representativo. Outra posição de autoria de destaque num artigo é como primeira autora, pois reflete em geral quem escreveu o artigo. Nesse caso, a porcentagem também foi muito baixa de apenas 13\% (22 artigos) para todas as revistas e não teve variação dependente do índice do impacto, aparentemente. Por fim, observa-se que se tem $21 \%$ dos artigos com autoria feminina em outras posições, ou seja, que não são nem a última ou primeira autora. Ou seja, mais mulheres em posições de "menor" destaque numa publicação científica.

Ainda, considerando as revistas com maior número de artigos, "Chemistry - A European Journal" e "Chemical Communication" que representam 52\% (89 artigos) de todas as publicações analisadas, observa-se uma baixa porcentagem de mulheres como última autora (2\%) e primeira autora (12\%). Possuem também alto índice de autoria sem mulheres brasileiras (56\%).

Ainda avaliando a Figura 6, observam-se os 20 artigos mais citados com alguma autoria durante vários períodos visto que quanto um artigo é citado também é uma forma de analisar o prestígio de um pesquisador. Nessa categoria, o dado mais alarmante está relacionado ao percentual de artigos sem autoria feminina. Considerando todo o período (1969-2018) e também os últimos 10 anos (2009-2018), ambos apresentam uma porcentagem alta que representa a maioria 


\section{AUTORIA POR MULHERES}

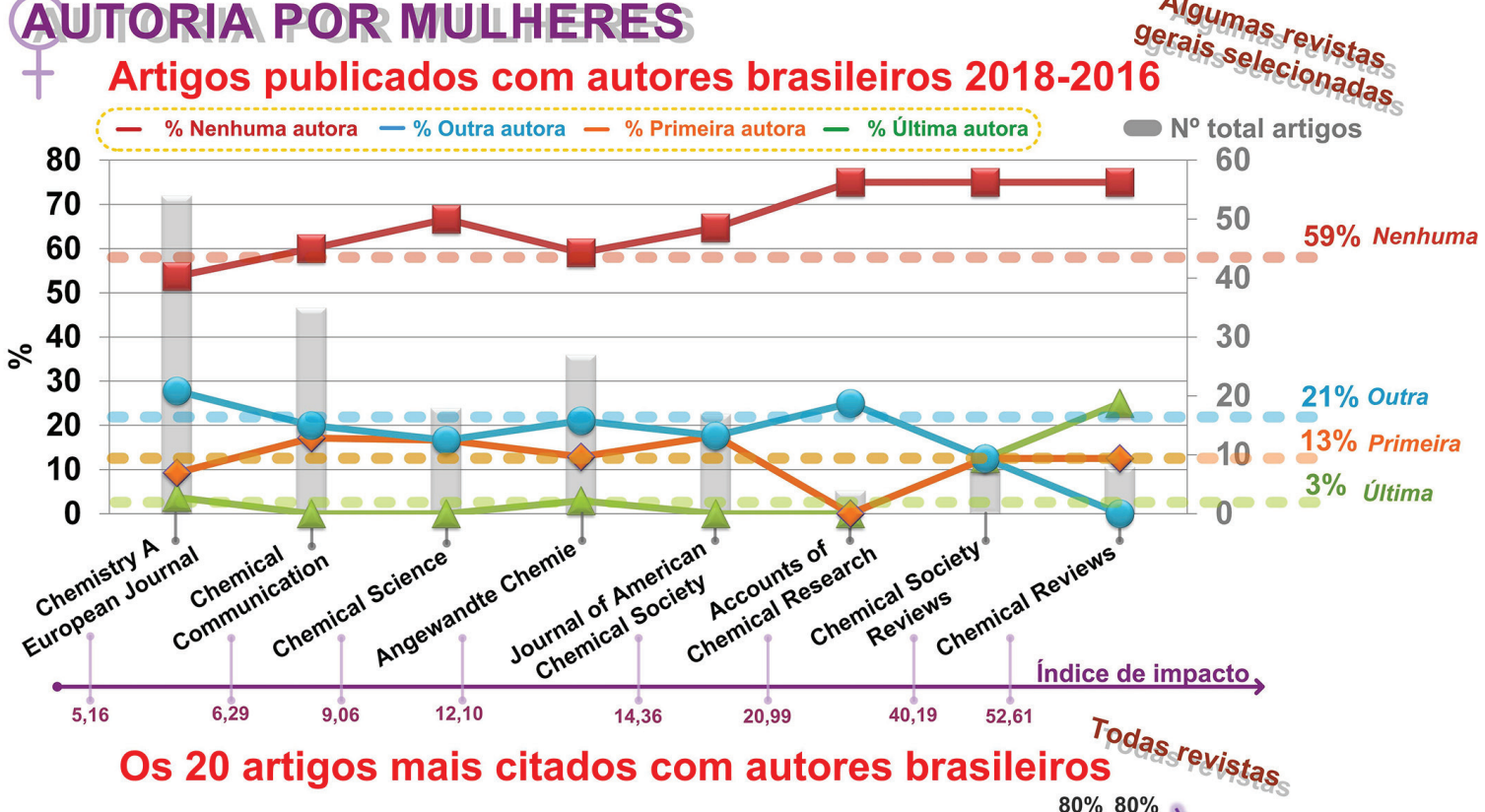

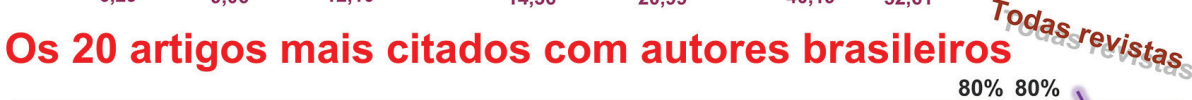

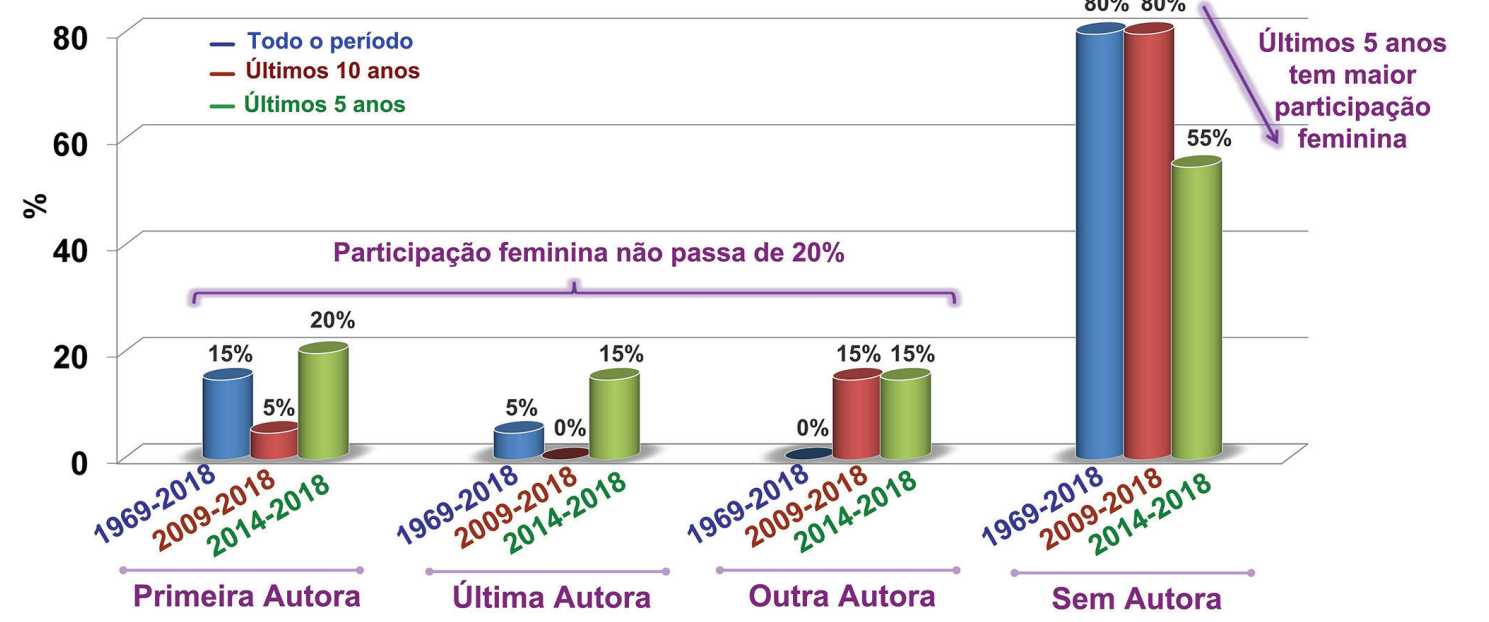

Figura 6. Representatividade das mulheres como primeira autora, última autora ou coautora em artigos publicados em algumas revistas internacionais gerais de química com índice de impacto (em 2019) e que continham vínculo com o Brasil no período de 2016-2018. No segundo gráfico, está descrita a representatividade feminina para os 20 artigos mais citados, com autoras brasileiras, considerando os últimos 10 e 5 anos e o período total. Fonte: Os dados foram coletados no site do Web of Science, em 05/2019

dos artigos selecionados (80\%) sem qualquer autora mulher. Contudo, observa-se que há uma mudança significativa nos últimos 5 anos (2014-2018) quando comparado aos períodos anteriores, em que houve uma queda de $80 \%$ para $55 \%$, indicando que o número de citações contendo participação feminina vem aumentando ao longo dos últimos anos.

Considerando os artigos que contêm mulheres como primeira autora dentre os 20 artigos mais citados (Figura 6), verifica-se um aumento expressivo na participação feminina nos últimos 5 anos quando comparado com os últimos 10 anos. Como observado no gráfico, essa porcentagem quadruplicou indo de $5 \%$ para $20 \%$ nas publicações examinadas. Porém, quando comparado este cenário dos últimos 5 anos com todo o período, esse aumento ainda é muito sutil, indo de $15 \%$ para $20 \%$. Esses dados mostram que houve uma queda brusca de crescimento no intervalo de 2009-2018.

Essa tendência oscilante entre os períodos também é observada para a porcentagem de artigos que contém mulheres como últimas autoras. Verifica-se que houve um aumento significativo nos últimos cinco anos comparativamente a todo período analisado e nos últimos 10 anos, variando de $5 \%$ e $0 \%$, respectivamente, para $15 \%$. Essa é uma análise importante, que mostra um aumento relevante na representatividade feminina na posição de maior destaque em autoria de artigo, visto que em geral a última autora é a pesquisadora com maior relevância científica. Apesar desses números indicarem um aumento na participação das mulheres na autoria desses artigos, esses valores ainda são inferiores a $20 \%$.

Para obter um parâmetro nacional das distribuições de mulheres em artigos publicados, foram analisadas as duas principais revistas brasileiras de Química: Journal of the Brazilian Chemical Society (JBCS) e Química Nova (QN) (Figura 7). Verificou-se o número de mulheres atuando como primeira, última e coautora para todos os artigos publicados com autores brasileiros (ano 2018) como também os 20 artigos mais citados nessas revistas em diferentes períodos.

Considerando os artigos publicados em 2018, observa-se que tanto para a JBCS quanto para a QN, as mulheres se apresentam como maioria para a posição de primeira autora. Para a JBCS, esse valor corresponde a 53\% do total (222 artigos) e, para a QN esse número é de $55 \%$ do total (138 artigos). Isso demonstra que nessas revistas brasileiras, há uma expressiva representatividade feminina para a posição de primeira autora. Contudo, no caso das últimas autoras, 
que corresponde geralmente a pesquisadora que submete o artigo, esse número diminui. Para a JBCS esse valor é de $31 \%$ e para a QN é de $36 \%$. Ou seja, essa menor porcentagem mostra que ainda há uma deficiência de mulheres como pesquisadoras em posições de destaque em artigos científicos.

Para os artigos sem autoria feminina (Figura 7), os números apresentam uma perspectiva mais positiva, uma vez que essa porcentagem é relativamente baixa, sendo de $13 \%$ para a JBCS e $20 \%$ para a QN. Esses números mostram uma maior paridade de gênero no cenário nacional, uma vez que nas revistas internacionais (2016-2018) essa porcentagem é 59\% (Figura 6). Demonstra-se, dessa forma, que a participação feminina como autoras em artigos nacionais é mais promissora quando comparado a análise em revistas internacionais (Figura 6).

Além disso, a Figura 7 avalia também os 20 artigos mais citados com autores brasileiros em ambas as revistas (JBCS e QN). Analisando os artigos sem autoria feminina, observa-se que há uma tendência positiva para JBCS uma vez que ao longo dos períodos essa porcentagem foi diminuindo, sendo de $30 \%$ para todo período analisado, 20\% para os últimos dez anos e $15 \%$ para os últimos cinco anos. Esses dados mostram que há um aumento na participação feminina em artigos científicos nessa revista. Para a QN, essa porcentagem não varia ao longo do período, porém, esse número é relativamente baixo, sendo de apenas $15 \%$ de artigos sem autoria feminina. Um ponto relevante dessa categoria é que nos últimos 5 anos, tanto para a JBCS quanto para a QN, essa porcentagem é de $15 \%$, enquanto para as revistas internacionais analisadas (Figura 6) esse número é $55 \%$.

Com relação aos artigos mais citados que tem mulheres como primeira autora (Figura 7), em ambas as revistas não há uma variação significativa ao longo dos anos, variando apenas cinco pontos percentuais. Analisando os últimos cinco anos, observa-se que a QN apresenta um cenário mais promissor quando comparado com a JBCS, sendo a porcentagem 40 e $25 \%$ respectivamente, como primeira autora.

Outro ponto avaliado são os artigos mais citados que possuem mulheres como última autora, sendo que a revista QN apresenta uma queda significativa da participação feminina nessa posição nos últimos anos. Em todo o período analisado, a porcentagem representava a maioria dos artigos (60\%), contudo nos últimos cinco anos houve uma queda expressiva nesse número, correspondendo apenas a 25\%. Para a revista JBCS esse valor se manteve constante ao longo dos anos, sendo de $25 \%$. Tanto para a QN quanto para a JBCS, nos últimos cinco anos, esse valor é de $25 \%$ sendo relativamente maior quando comparado com as revistas internacionais (15\%). Todos os pontos discutidos mostram que as mulheres têm uma maior representatividade no cenário nacional.

\section{AUTORIA POR MULHERES EM REVISTAS SBQ - Artigos publicados com autores brasileiros em 2018}

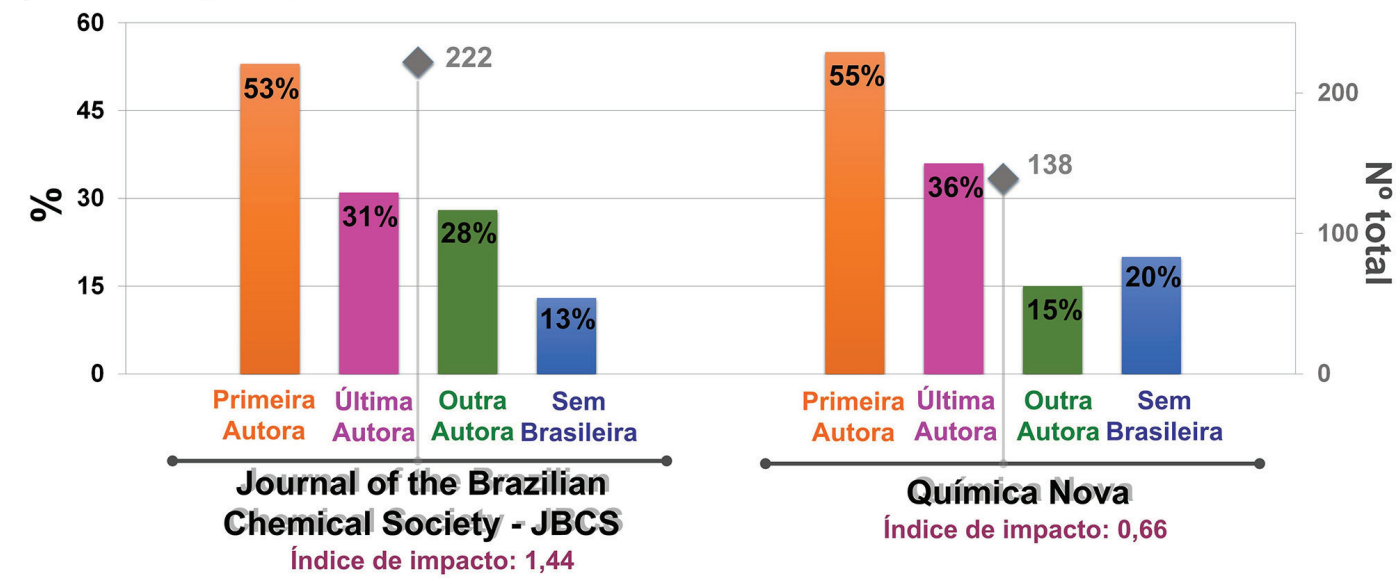

Os 20 artigos mais citados com autores brasileiros

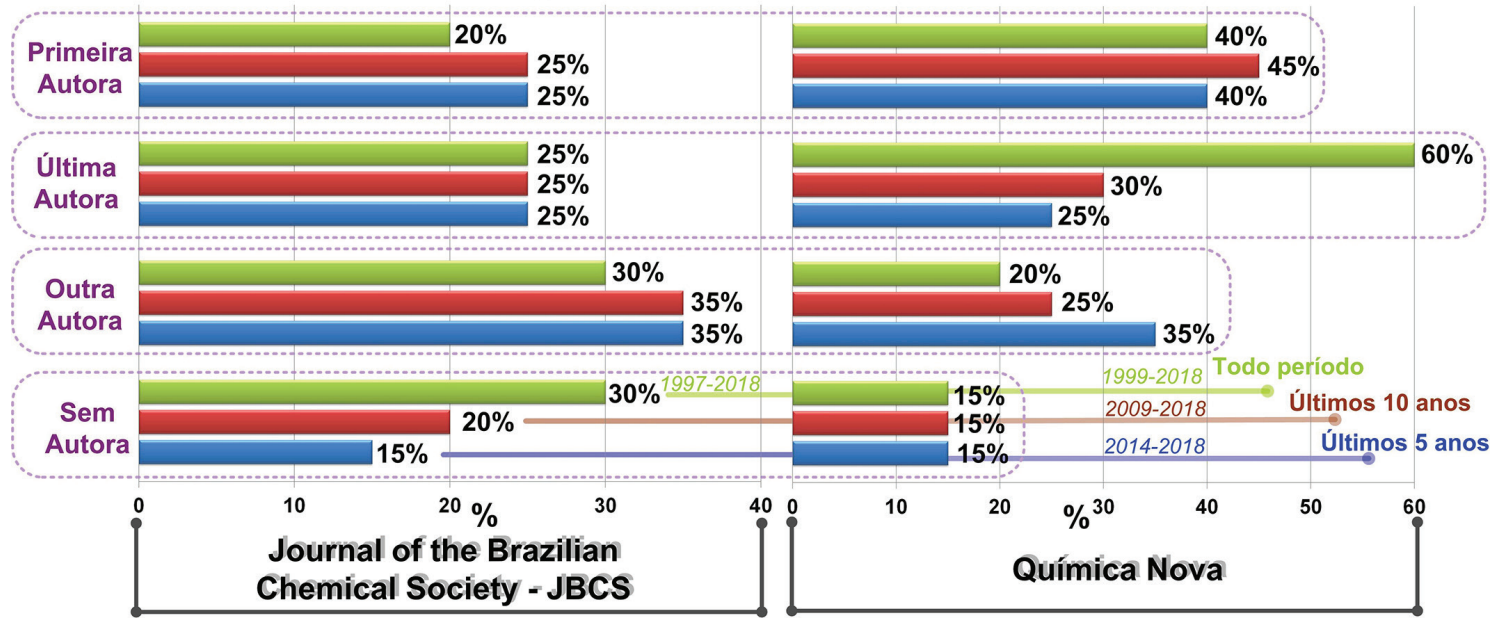

Figura 7. Distribuição de mulheres brasileiras como primeira, última e coautoras em artigos publicados no ano de 2018 e 20 artigos mais citados no JBCS e QN, em diferentes períodos. Fonte: os dados foram obtidos no site do Web of Science no período 05/2019 


\section{POUCAS (E MUITAS) MULHERES CIENTISTAS: EFEITO TESOURA NA QUÍMICA BRASILEIRA}

O cenário apresentado neste trabalho evidencia a representatividade das mulheres em diferentes áreas da carreira científica. De acordo com a Figura 8, que resume todos os níveis da progressão científica da mulher no Brasil, com suas respectivas porcentagens por níveis e cargos, nota-se que há uma tendência de queda na representatividade feminina conforme aumenta o nível do cargo.

Existe uma equidade na quantidade de mulheres e homens nos estágios iniciais da carreira, sendo que para alunos de iniciação cientifica e pós-graduação as mulheres representam a maioria, sendo respectivamente 56 e 52\%. Embora haja uma diminuição nesse número para docentes de $3^{\circ}$ grau e para coordenadores de graduação e pós-graduação, a queda não é tão significativa como em outros cargos mais elevados. No caso dos docentes de $3^{\circ}$ grau, as mulheres são praticamente metade nesses cargos, sendo $42 \%$ e nas coordenações a representatividade feminina é de $39 \%$. Porém, conforme os cargos vão progredindo, como no caso das bolsas de produtividade $\mathrm{CNPq}$, a porcentagem de mulher diminui. Nota-se que no nível 2 de produtividade, a porcentagem de mulheres já é bem menor em relação aos docentes de $3^{\circ}$ grau $(34 \%)$ e esse número diminui ainda mais quando o nível de produtividade aumenta, sendo de apenas 28 , 31 e $21 \%$ para $1 \mathrm{D}, 1 \mathrm{C}$ e $1 \mathrm{~B}$, respectivemente, e $12 \%$ para $1 \mathrm{~A}$, que é o nível mais alto de produtividade que um cientista pode alcançar. Quando analisamos a quantidade de projetos Universal do CNPq aprovados para as pesquisadoras, fica evidente a baixa quantidade de pesquisadoras agraciadas com os projetos faixa $\mathrm{C}$, que pode ser reflexo da baixa quantidade de pesquisadoras em estágios de maior prestígio científico (pesquisadoras 1A). A aprovação de projeto Universal possibilita o desenvolvimento de pesquisas, refletindo nas publicações científicas realizadas por mulheres, que também é baixa.

O contraste da representatividade feminina se torna muito evidente quando analisamos a presença das mulheres nas posições de prestígio acadêmico e cargos competitivos nas sociedades científicas. Os cargos de presidência em grandes organizações, como em FAPs, possuem uma representatividade de $8 \%$ de mulheres (2019) e as sociedades científicas, academia e órgãos de fomento, tem apenas $4 \%$ de mulheres como presidenta em todo o período analisado. Além disso, em 2019, as mulheres representavam apenas $18 \%$ dos membros na Academia Brasileira de Ciências, que é um dos maiores prestígios na carreira de um cientista no Brasil.

Outro indicativo que mostra a queda na participação feminina, está relacionado com as publicações em revistas nacionais e internacionais. Os dados obtidos mostram que há um baixo número de mulheres publicando em revistas internacionais bem conceituadas, sendo a porcentagem para última autora de $3 \%$. Além disso, nos 20 artigos mais citados com autoria brasileira dentre todas revistas, essa porcentagem, apesar de mostrar uma perspectiva de crescimento, continua muito baixa, sendo de $5 \%$ para todo o período analisado e 15\% em 2018 a 2019. Já nas revistas nacionais, embora o número represente minoria na participação feminina, o cenário se mostrou mais positivo para as mulheres, visto que sua participação aumentou consideravelmente, sendo $43 \%$ para todo o período analisado e $33 \%$ no ano de 2018.

Historicamente a questão dos estereótipos é apontada como um fator determinante para a falta de equidade de gênero nas ciências exatas. Tais estereótipos induzem a uma maior associação do homem com o desenvolvimento intelectual em comparação as mulheres para área de exatas..$^{21-23}$ Nesse sentido, há um preconceito maior com as mulheres, uma vez que são constantemente associadas a rótulos já estabelecidos para o sexo feminino, como sensíveis, emocionais e com dificuldades em cálculos matemáticos. ${ }^{6}$ Entretanto, no cenário atual do Brasil, apesar desses estereótipos relacionados às ciências exatas, verifica-se que na área de química as mulheres têm mostrado um volumoso interesse na área científica. Com cerca de 50\% de mulheres realizando IC, mestrado e doutorado, fica evidente o interesse e a inserção do sexo feminino na área de pesquisa científica. Esses números do início da carreira podem ser um reflexo de um conjunto de fatores sociais e culturais que ocorreram nos últimos anos. A grande questão então fica relacionada a pouca representatividade feminina nas posições de prestígio e que configuram o topo da carreira científica nesta área.

Além disso, o efeito de diminuição das mulheres em posições mais elevadas da carreira, também pode estar associado ao momento da vida no qual as escolhas pessoais e profissionais precisam concordar. Um desses momentos está relacionado ao período da maternidade, em que seus direitos e necessidades precisam ser observados. Alguns eventos científicos já tomaram iniciativas bastante interessantes e que podem ser amplamente divulgadas: espaços para acolhimento

\section{Carreira da mulher cientista no brasil}

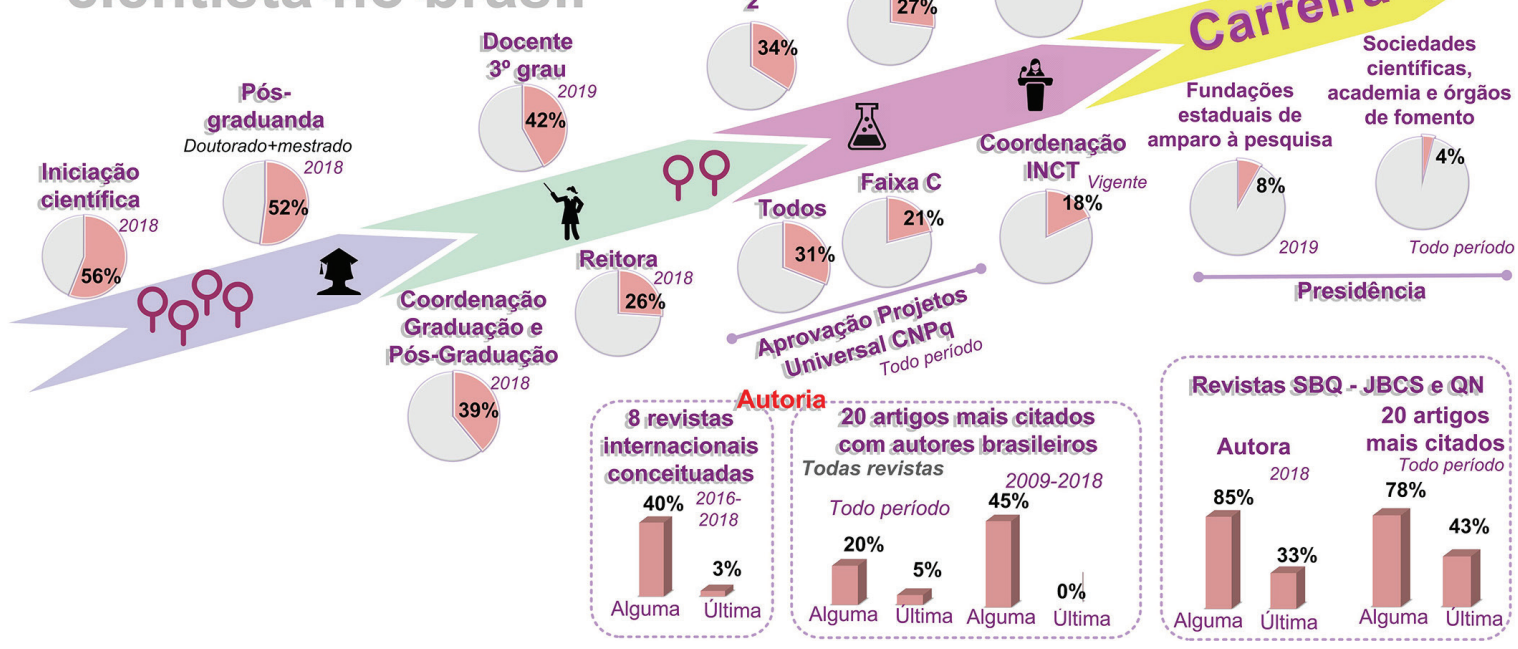

Figura 8. Ilustração da progressão da carreira científica da mulher no Brasil 
com trocadores, lugares específicos para amamentação e também a possibilidade de levar um acompanhante cuidador sem custos em eventos científicos. Além disso, creches nas universidades seriam importantes quando esse momento acontece nos períodos iniciais da carreira. Esses são apenas alguns exemplos e sugestões, mas muito ainda pode ser discutido a esse respeito, pois super-heroínas existem apenas no imaginário. É preciso suporte para que se possa competir profissionalmente. Dessa forma, tomando as medidas necessárias é possível que no futuro a quantidade de mulheres em posição de destaque seja favorecida.

Nessa perspectiva, a falta de referências femininas em papéis de liderança atualmente é um desencorajamento para que as mulheres obtenham posições de destaque na química. ${ }^{24} \mathrm{~A}$ mudança nesse contexto precisa vir através de políticas e ações afirmativas que impulsionem a carreira da mulher e promovam a sua inserção nos meios mais competitivos. Do contrário, a mudança desse cenário se dará de forma bastante lenta. Os benefícios vão muito além de simplesmente saber que se está abrindo as portas à participação feminina na ciência. A ciência é fortalecida e melhora a sua performance quando a diversidade está presente.

\section{FONTE DOS DADOS COLETADOS}

A distinção de gênero foi realizada manualmente, considerando o primeiro nome, visto que os nomes brasileiros são conhecidos por não possuírem muita ambiguidade em relação à atribuição de gênero ao nome. Os dados foram coletados entre 2018-2019 e em alguns casos se referem a um período maior (e.g. presidentes de sociedades científicas durante toda a existência).

Referente a Figura 1, avaliou-se o número de bolsistas de IC (na graduação) com bolsa vigente em 2018 na área de Química (totalizou 1243 bolsistas), disponível no site do CNPq. ${ }^{9}$ Para os alunos de doutorado e mestrado, os dados foram coletados no ano de 2018 referentes aos discentes que concluíram ou estavam em andamento no ano de 2017, obtidos a partir dos mecanismos de busca presentes na Plataforma Sucupira da Coordenação de Aperfeiçoamento de Pessoal de Nível Superior (CAPES) ${ }^{10}$ que totalizou 4230 e 3642 discentes de doutorado e mestrado, respectivamente. Foram considerados todos os estudantes estrangeiros e brasileiros, bolsistas ou não bolsistas, com registro vinculado às universidades e Institutos de Ensino Superior, de caráter público ou privado, que possuem Programa de Pós-Graduação (PPG) na área de Química. Referente à análise do Prêmio CAPES de Tese, avaliou-se os perfis do gênero dos vencedores desse prêmio na modalidade menção honrosa e Prêmio CAPES Tese, na área da Química (período de 2006 a 2018).

Para compilar os dados da Figura 2, avaliaram-se as mulheres atuantes como docentes, na área de Química, nos cursos graduação e pós-graduação, sendo que foram consideradas somente as universidades federais e estaduais que continham curso de Química ou Departamento de Química (ver Material Suplementar) na modalidade presencial, e desconsiderados os Institutos Federais e Tecnológicos. Para a coleta de dados dos cursos de graduação das universidades federais, foi utilizado o Portal da Transparência do Governo Federal (ano base 2019). ${ }^{12}$ Enquanto que para os cursos de graduação em universidades estaduais, os dados foram obtidos a partir do site de cada universidade, excluindo poucas situações em que o site estava desatualizado (ver material suplementar). Para os dados de docentes de pós-graduação (PPG), utilizou-se a plataforma Sucupira da CAPES considerando a área de Química vinculada às universidades de caráter público ou privado no qual foram examinados apenas docentes permanentes credenciados no programa no ano de 2018. Foram analisados um total de 55 universidades e 62 programas de pós-graduação, totalizando 2317 docentes vinculados a cursos de graduação e 1762 docentes credenciados a PPG na área de Química. Também foram analisados os programas de pós-graduação com conceito 6 (total de 6 programas, com 241 docentes credenciados) e 7 (total de 10 programas, com 528 docentes credenciados) segundo a avaliação da CAPES.

Referente à Figura 3, os dados das bolsas de produtividade foram obtidos utilizando o mecanismo de busca presente na base dados do CNPq. ${ }^{7}$ Nos níveis 1A, 1B, 1C, 1D e 2 foram considerados todos os pesquisadores com bolsa vigente durante o ano de 2018. Para o nível Pós-Doc foi utilizado o mecanismo de busca presente na plataforma Sucupira da CAPES, ${ }^{10}$ no qual foram considerados todos os bolsistas vinculados às universidades, pública ou privada, e programas de Química, utilizando o ano base 2019. A representação feminina dentre os membros titulares da ABC foram obtidos diretamente do site da Academia em Junho/2019. ${ }^{14}$ Para os dados de bolsa de produtividade analisou-se um total de 61 bolsistas para o nível 1A, 57 para o 1B, 61 para 1C, 102 para 1D e 413 para o nível 2, enquanto que para Pós-Doc foi obtido um número total de 371 bolsistas.

Para os dados da Figura 4, os dados dos Projetos Universais aprovados entre o período de 2007 a 2018 foram obtidos do site do CNPq verificando os resultados de cada edital na área de Química.

Com relação a Figura 5, as informações referentes a reitoria e coordenação de graduação foram obtidas pelo mecanismo de busca presente no site do Ministério da Educação (MEC) (ano base 2019). ${ }^{11}$ Foram considerados os coordenadores e reitores de instituições de ensino superior de caráter público (Federal ou Estadual) e que possuem o curso de Química, licenciatura ou bacharelado, da modalidade presencial. Para as informações de coordenadores dos PPG foi utilizada a plataforma sucupira (ano base 2018) na área de avaliação de Química considerando instituições de caráter público e privado. Foram contabilizados um total de 173 coordenadores de cursos de graduação, 91 reitores e 66 coordenadores de PPGs.

Foram analisados os artigos publicados em algumas revistas reconhecidas internacionalmente que continham autoria com vínculo brasileiro no período de 2016-2018, dados na Figura 6. Os dados estão mostrados em função da porcentagem de mulheres como primeira autora, última autora, outra autora (não sendo última ou primeira) e quando não tem nenhuma mulher brasileira na autoria (171 artigos analisados). O número total de artigos também está mostrado, bem como o índice de impacto das revistas (em 2019). Também são mostrados os dados dos 20 artigos mais citados com alguma autoria brasileira durante vários períodos (todo período, 10 últimos anos e 5 últimos anos). Os dados foram coletados no site do Web of Science, em 05/2019.

Para os dados da Figura 7, analisaram-se duas das principais revistas brasileiras na área: Journal of the Brazilian Chemical Society (JBCS) e Química Nova (QN). Para ambas, verificou-se o número de mulheres atuando como primeira, última e coautora para todos os artigos publicados com autores brasileiros no ano de 2018. Além disso, também foram analisados dados para os 20 artigos mais citados nessas revistas em todo o período (1999-2018) e para os últimos 10 (2009-2018) e 5 anos (2014-2018).

\section{MATERIAL SUPLEMENTAR}

Os dados utilizados para a produção dos gráficos apresentados neste trabalho estão disponíveis em http://quimicanova.sbq.org.br, na forma de arquivo PDF, com acesso livre.

\section{AGRADECIMENTOS}

As autoras agradecem à UFPR, ao Instituto Nacional de Ciência e Tecnologia em Nanomateriais de Carbono (INCT-Nanocarbono), 
à CAPES, ao CNPq, à PhosAgro/UNESCO/IUPAC, Fundação Araucária e L'Oréal-UNESCO-ABC. O presente trabalho foi realizado com apoio da Coordenação de Aperfeiçoamento de Pessoal de Nível Superior - Brasil (CAPES) - Código de Financiamento 001.

\section{REFERÊNCIAS}

1. https://nacoesunidas.org/artigo-a-importancia-de-promover-liderancafeminina-na-america-latina/, acessada em maio de 2020.

2. https://www.ilo.org/global/research/global-reports/weso/trends-forwomen2017/WCMS_557245/lang--en/index.htm, acessada em maio de 2020.

3. IBGE; Estudos e Pesquisas, Informação Demográfica $e$ Socioeconômica; 2018; 38; ISBN 978-85-240-4448-9.

4. OECD (2018), "Brazil", in Education at a Glance 2018: OECD Indicators, OECD Publishing: Paris, 2018, DOI: https://doi.org/10.1787/ eag-2018-73-en.

5. Elsevier, Gender in the Global Research Landscape, 2017, disponível em https://www.elsevier.com/__data/assets/pdf_file/0008/265661/ ElsevierGenderReport_final_for-web.pdf, acessado em maio de 2020.

6. Santos, N. C. F.; Valli, M.; Bolzani, V. d. S.; Pure Appl. Chem. 2019, 91, 743.

7. Albornoz, M.; Barrere, R.; Matas, L.; Osorio, L.; Sokil, J.; Papeles del observatorio $n^{\circ} 09,2018$, ISSN: 2415- 1785
8. Marcia C. Barbosa, Lima, B. S.; Mulheres na Física do brasil: Por que tão poucas? E por que tão devagar?; Trabalhadoras: Análise da Feminização das Profissões e Ocupações, Yannoulas, S. C., coord.; 1 ed., Abare: Brasilia, 2013, pp. 69-86.

9. http://www.cnpq.br/, acessada em maio de 2020.

10. https://sucupira.capes.gov.br, acessada em maio de 2020.

11. http://www.mec.gov.br, acessada em maio de 2020.

12. http://www.portaltransparencia.gov.br/, acessada em maio de 2020 .

13. http://m.ruf.folha.uol.com.br/2018/, acessada em maio de 2020

14. http://www.abc.org.br, acessada em maio de 2020.

15. http://www.sbq.org.br/, acessada em maio de 2020.

16. https://iupac.org/, acessada em maio de 2020.

17. http://portal.sbpcnet.org.br/, acessada em maio de 2020.

18. https://www.capes.gov.br, acessada em maio de 2020.

19. http://confap.org.br/, acessada em maio de 2020.

20. Cross, D.; Thomson, S.; Sibclair, A.; Research in Brazil: A report for CAPES by Clarivate Analytics; Clarivate Analytics: Pennsylvania, 2018.

21. Huber, R. A.; Burton, G. M.; Sch. Sci. Math. 1995, 95, 371.

22. Cvencek, D.; Meltzoff, A. N.; Greenwald, A. G.; Child Dev. 2011, 82, 766.

23. Bian, L.; Leslie, S. J; Cimpian, A.; Science 2017, 355, 389.

24. Schiebinger, L.; O feminismo mudou a ciência? Bauru-SP, EDUSC, 2001 [original em inglês: Has feminism changed science? Cambridge, Harvard University Press, 1999]. 